\title{
p38MAPK builds a hyaluronan cancer niche to drive lung tumorigenesis
}

\author{
Anna Brichkina, ${ }^{1,7}$ Thomas Bertero, ${ }^{2}$ Hui Mun Loh, ${ }^{1}$ Nguyet Thi Minh Nguyen, ${ }^{1}$ \\ Alexander Emelyanov, ${ }^{2,3,4,5,6}$ Sidwell Rigade, ${ }^{2}$ Marius Ilie, ${ }^{2,3,4,5,6}$ Paul Hofman, ${ }^{2,3,4,5,6}$ \\ Cedric Gaggioli, ${ }^{2,3,4,5}$ and Dmitry V. Bulavin ${ }^{2,3,4,5,6}$ \\ ${ }^{1}$ Institute of Molecular and Cell Biology, A*STAR (Agency for Science, Technology, and Research), Biopolis, Singapore 138673; \\ ${ }^{2}$ Institute for Research on Cancer and Aging of Nice (IRCAN), Nice 06107, France; ${ }^{3}$ U1081, INSERM (Institut National de la Santé \\ et de la Recherche Médicale), Nice 06107, France; ${ }^{4}$ UMR 7284, CNRS (Centre National de la Recherche Scientifique), Nice 06107, \\ France; ${ }^{5}$ University of Nice-Sophia Antipolis, Nice 06300, France; ${ }^{6}$ Centre Antoine Lacassagne, Nice 06100, France
}

Expansion of neoplastic lesions generates the initial signal that instigates the creation of a tumor niche. Nontransformed cell types within the microenvironment continuously coevolve with tumor cells to promote tumorigenesis. Here, we identify p38MAPK as a key component of human lung cancer, and specifically stromal interactomes, which provides an early, protumorigenic signal in the tissue microenvironment. We found that lung cancer growth depends on short-distance cues produced by the cancer niche in a p38-dependent manner. We identified fibroblast-specific hyaluronan synthesis at the center of p38-driven tumorigenesis, which regulates early stromal fibroblast activation, the conversion to carcinoma-associated fibroblasts (CAFs), and cancer cell proliferation. Systemic down-regulation of p38MAPK signaling in a knock-in model with substitution of activating Tyr182 to phenylalanine or conditional ablation of p38 in fibroblasts has a significant tumor-suppressive effect on K-ras lung tumorigenesis. Furthermore, both Kras-driven mouse lung tumors and orthotopically grown primary human lung cancers show a significant sensitivity to both a chemical p38 inhibitor and an over-the-counter inhibitor of hyaluronan synthesis. We propose that p38MAPK-hyaluronan-dependent reprogramming of the tumor microenvironment plays a critical role in driving lung tumorigenesis, while blocking this process could have far-reaching therapeutic implications.

[Keywords: fibroblasts; hyaluronan; p38MAPK; lung cancer; tumor microenvironment]

Supplemental material is available for this article.

Received September 5, 2016; revised version accepted November 22, 2016.

Cancer is a complex systemic disease in which many normal cells are recruited to the tumor site to sustain malignant growth (Junttila and de Sauvage 2013). The initial expansion of cancer cells generates a signal to create the cancer niche; however, it is not clear which type of normal cell responds first to the initial tumor growth. Evidence has indicated that fibroblasts were among the first cells to be recruited by tumor cells; however, it is widely accepted that normal fibroblasts generally suppress tumor formation (Dotto et al. 1988; Junttila and de Sauvage 2013). To promote tumorigenesis, normal fibroblasts must be educated by cancer cells in the process of conversion to carcinomaassociated fibroblasts (CAFs) (Orimo et al. 2005). Once accomplished, this will result in extensive tissue remodeling (Joyce and Pollard 2009; Gascard and Tlsty 2016). Further establishment of a complex, dynamic network of cytokines, chemokines, growth factors, and matrix remodeling

\footnotetext{
${ }^{7}$ Present address: Institute of Molecular Oncology, Center for Tumor and Immunobiology, Philipps University, Marburg, Germany. Corresponding author: dmitry.bulavin@unice.fr

Article is online at http://www.genesdev.org/cgi/doi/10.1101/gad.290346. 116.
}

enzymes ultimately changes the physical and chemical properties of the tumor. Additionally, this dynamic tumor-promoting microenvironment is expanded by recruiting immune cells, pericytes, and sometimes adipocytes and establishing tumor vasculature and lymphatics.

Lung cancer causes the largest number of cancer-related deaths worldwide. More than $85 \%$ of lung cancers are currently classified as non-small cell lung cancer (NSCLC), with a predicted 5-year survival rate of only $15.9 \%$ (Chen et al. 2014). It becomes increasingly clear that the effective approach to treating lung cancer will require therapies that can target both tumor cells and tumor-associated components. Stromal cells, such as fibroblasts, are known to provide signals to support tumor growth and survival, but no drug options exist that successfully target this component of the tumor microenvironment.

(C) 2016 Brichkina et al. This article is distributed exclusively by Cold Spring Harbor Laboratory Press for the first six months after the full-issue publication date (see http://genesdev.cshlp.org/site/misc/terms.xhtml). After six months, it is available under a Creative Commons License (Attribution-NonCommercial 4.0 International), as described at http://creativecommons.org/licenses/by-nc/4.0/. 
p38MAPK (MAPK14) has been implicated in the regulation of different cancerous and noncancerous cell types that could be found in the tumor microenvironment (Alspach et al. 2014; Igea and Nebreda 2015). Originally, p38MAPK was proposed as a potential cancer suppressor (Brancho et al. 2003; Bulavin and Fornace 2004). However, its role in tumorigenesis has remained highly controversial. Initial experiments in mouse cancer models showed that p38MAPK suppressed lung and liver tumor formation in vivo (Hui et al. 2007; Ventura et al. 2007). However, enhanced p38MAPK activation and overexpression were reported in different human cancers, including lung tumors, and, in some cases, correlated with a poor prognosis (Greenberg et al. 2002; ElenitobaJohnson et al. 2003; Pomerance et al. 2006). A definitive conclusion about the role of p38MAPK in cancer has been prevented by, among other reasons, the lack of models with systemic p38MAPK inactivation because conventional knockouts are embryonic-lethal (Adams et al. 2000; Tamura et al. 2000). Here we overcame this problem by substituting the p38MAPK-activating site Tyr182 with Phe. This genetic change resulted in significant down-regulation of p38MAPK signaling, and cancer cells carrying this mutation appeared to be more tumorigenic. In sharp contrast, in a mouse model of Kras-driven tumorigenesis, this systemic inactivation of p38MAPK caused profound tumor resistance. This effect appeared to be non-cell-autonomous and independent of p53 and relied on p38MAPK activation in fibroblasts at the tumor site.

\section{Results}

In silico network-based analysis identifies p38MAPK as a master NSCLC regulator

To determine novel, important molecular regulators in NSCLC pathogenesis, we constructed an in silico network of genes and interactions. We compiled transcriptomic data sets of cancer tissues and compared them with paired, noncancer control transcriptomic data sets ( $n=60)$ from publically available databases (GSE19804). We called the complete network the "expanded NSCLC network" (Fig. 1A; Supplemental Table 1). Next, we ranked genes according to a hypergeometric analysis of the number of NSCLC-relevant interactions, accounting for the expanded NSCLC network size and the total number of targets for each gene. The top-ranked genes would be expected to be highly influential in the context of NSCLC (a high betweenness centrality score and a large number of interacting clusters), and we identified the members of the MAPK14 (p38MAPK) signaling pathway among the top 20 genes (Supplemental Table 2).

To identify genes with a holistic effect on NSCLC progression, we reasoned that they should exert a hierarchical control over the most influential genes. In order to identify such overarching regulator genes, we analyzed the hierarchy of the top 20 highly influential genes. Using this approach, we identified p38MAPK as one of the top five interactomes in the NSCLC (Fig. 1B; Supplemental Table
3). Based on gene function annotations derived from the Kyoto Encyclopedia of Genes and Genomes, Reactome, and NCBI BioSystems databases as well as reports in the scientific literature, we identified 57 targets of MAPK14 (p38MAPK) representing a total of 19 out of the top 20 functional pathways that were embedded throughout the network. Our analysis strongly argues that the p38MAPK pathway represents a potentially important molecular regulator in NSCLC pathogenesis.

\section{p38MAPK promotes lung tumorigenesis in a non-cell- autonomous manner}

The in silico analysis provided evidence for a potential role of p38MAPK in human NSCLC. Next, we turned to a mouse model of lung cancer induced with a somatic expression of a mutant Kras gene (KRAS ${ }^{\mathrm{G} 12 \mathrm{D} /+}$ ) (Johnson et al. 2001). We found that both p38 and its downstream target, MK2, were highly phosphorylated in tumor lesions (Fig. 1C). The staining was most intense at the edges of the tumor area (Supplemental Fig. S1A). This provided direct evidence that p38MAPK was activated in KRAS lesions and could potentially play a role in lung cancer progression. To address the systemic role of p38MAPK, we decided to generate a novel mouse model with attenuated p38 activity throughout all cell types. A previous analysis revealed that mice with double mutations in p38MAPK at the activating sites, Thr180 and Tyr182, fully resembled the p38MAPK knockout phenotype (i.e., early embryonic-lethal) (Wong et al. 2009). This information provided a potential direction for further genetic manipulations. First, we evaluated whether mutating a single phosphorylation site would affect p38 signaling and the mouse phenotype. We generated two knock-in mouse lines: One substituted Thr180 with Ala (T180A), and the other substituted Tyr182 with Phe (Y182F). Our analysis revealed that homozygous T180A knock-in mice had an embryonic-lethal phenotype identical to the double mutants (Wong et al. 2009) and conventional knockouts (Adams et al. 2000; Tamura et al. 2000). In contrast, homozygous Y182F knock-in mice (p38 ki/ki) were viable and were used for further analysis.

To determine the extent of the change caused by this genetic manipulation in p38MAPK signaling, we crossed wild-type mice $\left(\mathrm{p} 38^{+/+}\right)$with $\mathrm{p} 38^{\mathrm{ki} / \mathrm{ki}}$ mice to create p38MAPK heterozygous mice $\left(\mathrm{p} 38^{\mathrm{ki} /+}\right)$ and established mouse embryonic fibroblast (MEF) cultures. We found that p38MAPK and Hsp27 phosphorylation was significantly reduced after UV irradiation or treatment with TNFa (Fig. 1D). In vivo, we found that $\mathrm{p} 38^{\mathrm{ki} / \mathrm{ki}}$ mice, similar to the treatment with a p38 inhibitor (Supplemental Fig. S1B), responded poorly to lipopolysaccharide and thioglycolate, which activated interleukin-6 (Il-6) and Il-10 in the lungs (Supplemental Fig. S1C).

To understand the role of systemic inactivation of p38MAPK in cancer, we crossed KRAS ${ }^{\mathrm{G} 12 \mathrm{D} /+}$ mice with p3 $8^{\mathrm{ki} /+}$ knock-in mice and investigated whether the phosphorylation levels of p38 and MK2 were changed on a p38 ${ }^{\mathrm{ki} / \mathrm{ki}}$ background. We found that phosphorylation was strongly reduced in knock-in mice (Fig. 1C). Next, we 
A

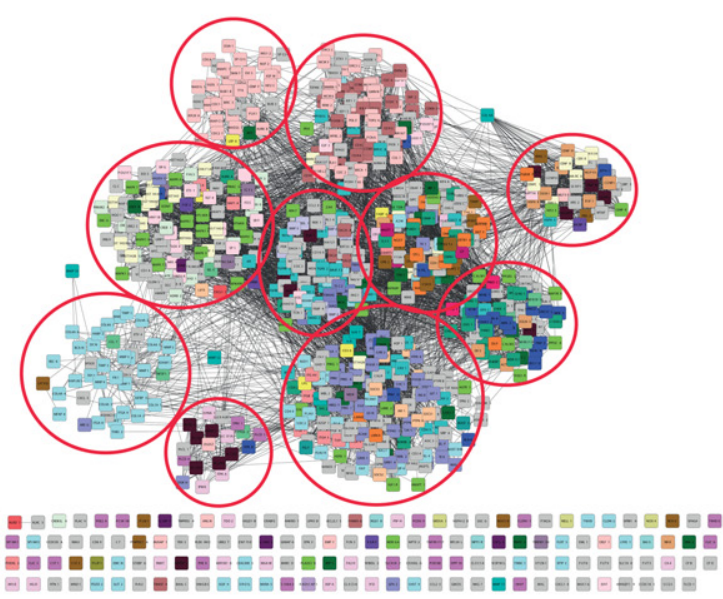

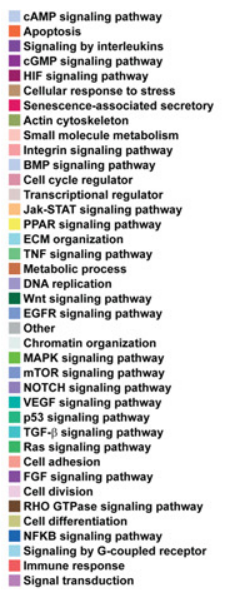

B

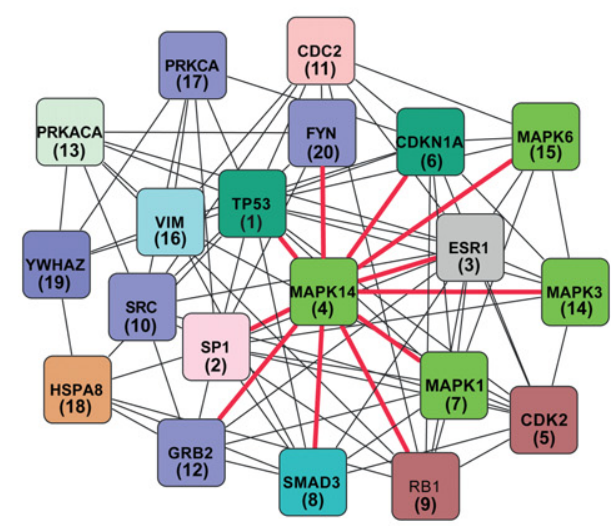

C

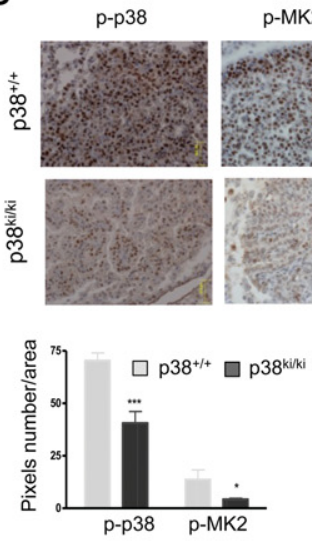

D
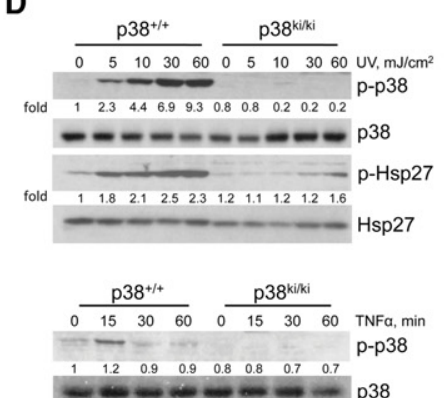

$-2-0=-\mathrm{p}-\mathrm{Hsp} 27$

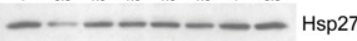

E

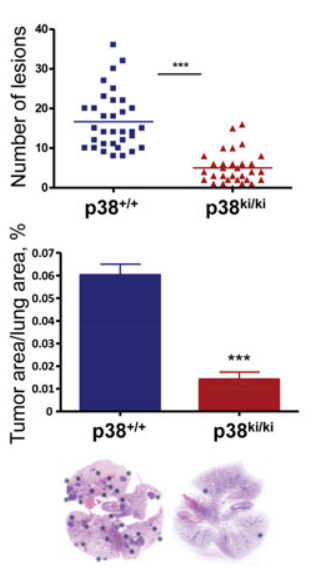

F

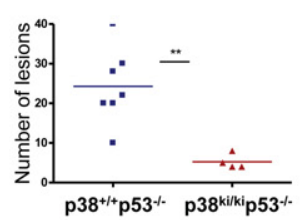

G

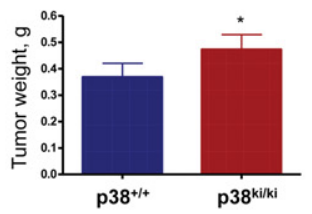

Figure 1. Activation of p38MAPK is required for lung tumorigenesis. $(A)$ The expanded NSCLC network is color-coded according to the functional pathway. Encircled areas represent architectural clusters based on a spectral partition-based clustering algorithm. p38MAPK (MAPK14) was ranked in the top 20 genes by the spanning score, reflecting a robust control over the expended NSCLC as a whole. The 57 direct targets of MAPK14 span all 10 gene clusters and 19 functional pathways. (B) Hierarchical ranking of the top 20 genes, color-coded by functional pathway, reveals MAPK14 as a system-level overarching regulator over the expanded NSCLC network. The ranking score is shown in the brackets. $(C)$ KRAS lung tissues stained with phospho-specific antibodies for p38 and MK2; representative images are shown with analysis of intensity. Mean \pm SD. $n=9$. $\left.\left(^{*}\right) P<0.05 ;{ }^{* * *}\right) P<0.001$. (D) Western blot analysis of mouse embryonic fibroblasts $($ MEFs) treated with different doses of UV radiation or TNFa treatment. The intensity was analyzed by densitometry. $(E)$ The numbers of lung tumor lesions in 10-wk-old KRAS p38 $8^{+/+}(n=33)$ and KRAS p38 $8^{\mathrm{ki} / \mathrm{ki}}(n=31)$ mice. Relative tumor area was calculated and is presented as the percentage relative to a total lung area $(n=6)$; note the dark hematoxylin/eosin-positive nodules (indicated with asterisks) representing tumor lesions. $\left(^{* * *}\right) P<0.001 .(F)$ The number of lung tumor lesions in 10 -wk-old KRAS p38 ${ }^{+/+}(n=7)$ and KRAS p38 $8^{\mathrm{ki} / \mathrm{ki}}(n=4)$ on a p53deficient background. $\left.{ }^{* *}\right) P<0.01$. (G) Primary lung tumor cell lines established from KRAS lung tumors from p38 $8^{+/+}$and p38 ${ }^{\mathrm{ki} / \mathrm{ki}} \mathrm{mice}$ were injected into nude mice, and tumors were analyzed as shown in the graph. $n=11$. All data are mean \pm SD. $\left(^{*}\right) P<0.05$.

analyzed lung lesions and found that the number and size of KRAS-driven tumor lesions were significantly reduced in 10 -wk-old $\mathrm{p} 38^{\mathrm{ki} / \mathrm{ki}}$ mice compared with $\mathrm{p} 38^{+/+}$mice (Fig. 1E). The number of lesions in $\mathrm{p} 38^{\mathrm{ki} / \mathrm{ki}}$ mice remained very low at later time points (e.g., 20-wk-old mice) (Supplemental Fig. S1D). The reduction in tumor lesions correlated with a significant reduction in the overall tumor area in $\mathrm{p} 38^{\mathrm{ki} / \mathrm{ki}}$ mice (Fig. 1E). Furthermore, inactivation of $\mathrm{p} 53$, which is commonly observed in human lung tumors, did not affect the tumor-resistant phenotype of $\mathrm{p} 38^{\mathrm{ki} / \mathrm{ki}}$ mice (Fig. 1F). These data suggested that p38MAPK controlled KRAS-driven lung cancer independently of p53.

Our results were rather unexpected because conditional deletion of p38MAPK in KRAS-driven lung lesions accelerated tumorigenesis (Ventura et al. 2007). To investigate this further, we established primary KRASdriven lung cancer cell cultures from $\mathrm{p} 38^{+/+}$and $\mathrm{p} 38^{\mathrm{ki} / \mathrm{ki}}$ mice. Next, we xenografted these cells into immunodeficient nude mice and found that the lung tumor cells with inactivated p38MAPK formed larger tumor masses than those formed with $\mathrm{p} 38^{+/+}$cells (Fig. 1G). Similarly, when p38 knock-in MEFs were transformed with E1A and Ras, they formed more aggressive tumors in xenografts (Supplemental Fig. S1E). These results suggested that the suppressed growth of KRAS-driven lung tumors in $\mathrm{p} 38^{\mathrm{ki} / \mathrm{ki}}$ mice did not depend on the intrinsic properties of the tumor cells. Consistent with this prediction, intravenously injected Lewis lung carcinoma (LLC) cells 
could not seed efficiently in mice with inactivated p38MAPK (Supplemental Fig. S1F). Taken together, our data pointed to the hypothesis that, in vivo, p38MAPK played a role in the microenvironment, which promoted lung tumorigenesis.

\section{p38MAPK activity in stromal fibroblasts is critical for lung tumorigenesis}

We first validated out hypothesis by building an in silico network of genes and interaction of specific lung tumor stromal transcriptomic data sets and compared them with paired noncancerous nonepithelial lung tissues (GSE22863). We called this network the "expanded NSCLC stromal network" (Fig. 2A; Supplemental Table 4). Similar to the expanded NSCLC network ranking of genes according to the hypergeometric analysis of the number of genes and subnetwork interactions, we ranked genes according to their influence on the stromal network (Fig. 2B; Supplemental Tables 5, 6). p38MAPK (MAPK14) was ranked among the top five for potential gene network regulatory significance, which could further emphasize the crucial role of p38MAPK in lung cancer stroma development during tumorigenesis.
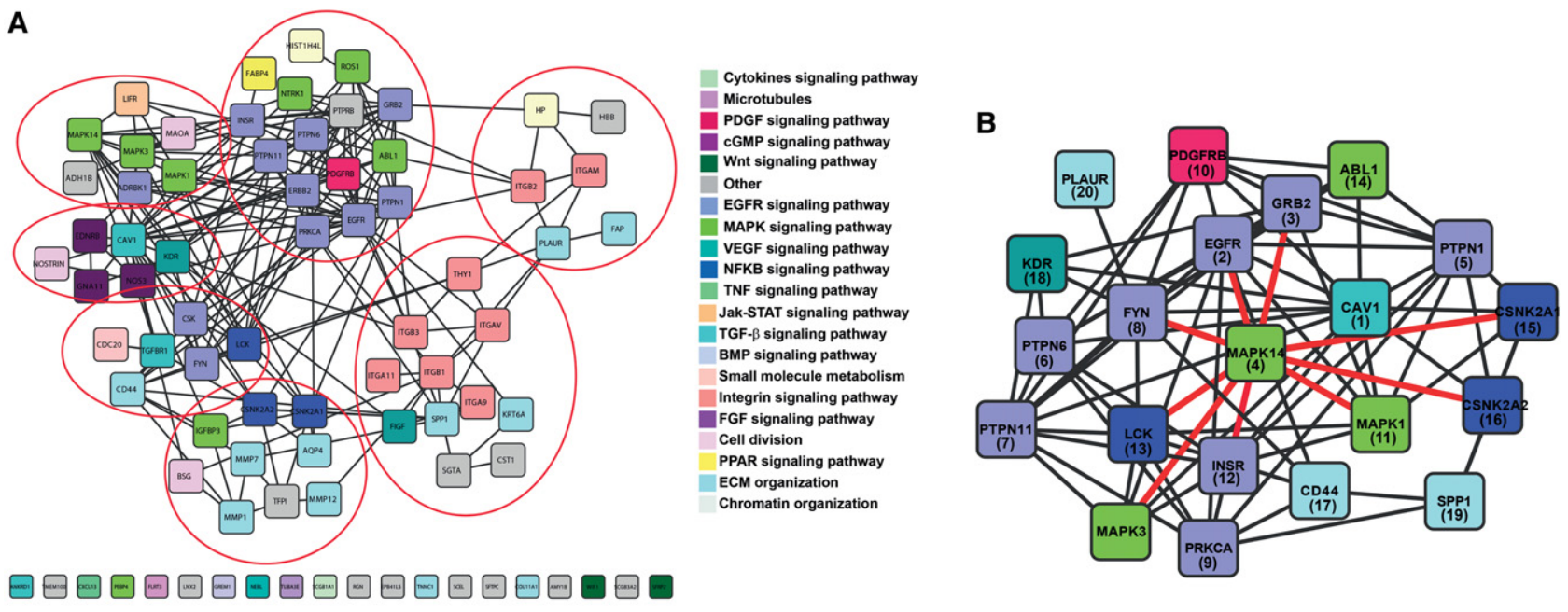

C
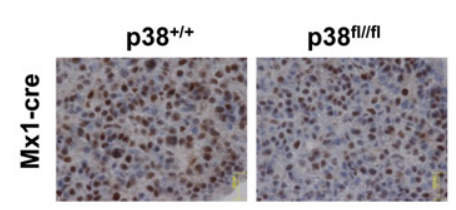

E

ㅎํㅁ

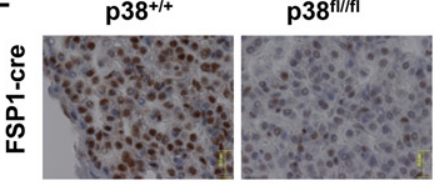

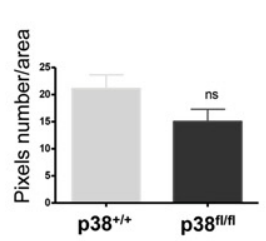

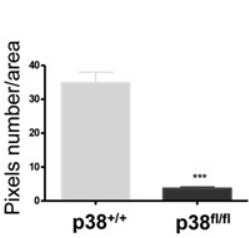

D

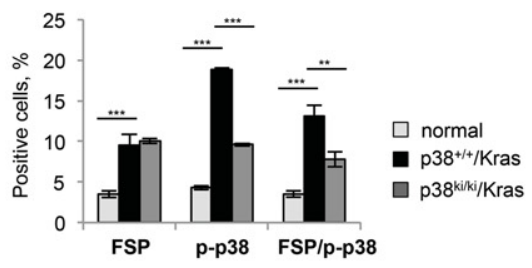

$\mathbf{F}$

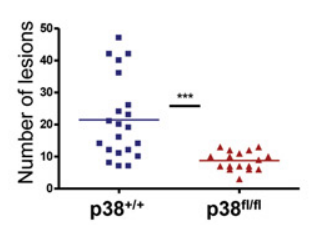

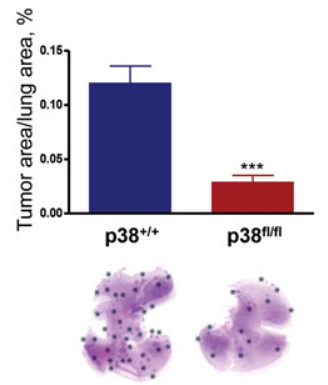

Figure 2. p38MAPK in stromal fibroblasts controls KRAS-driven lung cancer. $(A)$ The expanded NSCLC stromal network is color-coded according to functional pathways. Circled areas represent architectural clusters based on the spectral partition-based clustering algorithm. p38MAPK (MAPK14) was ranked in the top 20 genes by the spanning score, reflecting a robust control over the expanded NSCLC stromal network as a whole. The 13 direct targets of MAPK14 span six gene clusters and six functional pathways. $(B)$ Hierarchical ranking of the top 20 genes, color-coded by functional pathway, reveals MAPK14 as a system-level overarching regulator over the expanded NSCLC stromal network. The ranking score is shown in the brackets. $(C)$ Lung tumor lesions in KRAS mice with conditional deletion of p38 in hematopoietic cells (Mx1-Cre) were stained with phospho-specific antibodies for MK2. The analysis is presented as the mean ratio of the pixel number to the tumor area \pm SD. (NS) Nonsignificant. $n=7$. (D) Percentage of FSP, phospho-p38 (p-p38), and double-FSP/p-p38 cells in the lungs of normal, $\mathrm{p} 38^{+/+}$, and $\mathrm{p} 38^{\mathrm{ki} / \mathrm{ki}} / \mathrm{KRAS}$ tumor-bearing mice. $n=3$. A representative FACS analysis is shown in Supplemental Figure S2E. $\left({ }^{* *}\right) P<0.01 ;\left(^{* * *}\right) P<0.001$. (E) Same as in $C$, but mice had a conditional deletion of p38 in stromal fibroblasts (FSP1-Cre). $\left(^{* * *}\right) P<0.001 . n=10 .(F)$ The number of lung tumor lesions at $10 \mathrm{wk}$ in wild-type p $38^{+/+}(n=21)$ and $\mathrm{p} 38^{\mathrm{fl} / \mathrm{fl}}(n=17)$ FSP1-Cre/KRAS mice. A relative tumor area was calculated as the percentage of total lung area. $\left.n=6 .{ }^{* * *}\right) P<0.001$ 
To validate the role of $\mathrm{p} 38 \mathrm{MAPK}$ in the establishment of a protumorigenic microenvironment in the course of KRAS-driven lung tumorigenesis, we next turned to in vivo analysis of different cell types that comprise the cancer niche. To address the role of immune cells in the up-regulation of p38MAPK signaling in KRAS lesions, we inactivated p38MAPK in the entire hematopoietic system by crossing mice that expressed a floxed allele of p38MAPK (Nishida et al. 2004) with Mxl-Cre. Of note, inactivation of p38MAPK did not significantly change blood cell profiles in healthy nontumor mice (Supplemental Fig. S2A). Two groups of mice, both carrying Mx1-Cre/ KRAS on either a $\mathrm{p} 38^{+/+}$or a $\mathrm{p} 38^{\mathrm{fl} / \mathrm{fl}}$ background, were subjected to $\mathrm{pI}-\mathrm{pC}$ injections, which successfully removed p38MAPK in the bone marrow of $\mathrm{p} 38^{\mathrm{fl} / \mathrm{fl}}$ mice (Supplemental Fig. S2B). Next, we immunohistochemically analyzed KRAS lesions and found that tumors on the $p 38^{\mathrm{fl} / \mathrm{fl}}$ Mx1-Cre background maintained high activation of p38MAPK signaling (Fig. 2C; Supplemental Fig. S2C). This suggested that nonhematopoietic cell types must have contributed primarily to p38MAPK activation in KRAS lung lesions.

Next, we hypothesized that p38MAPK activation in stromal fibroblasts might contribute to p38 activation at the tumor site and potentially to KRAS-driven tumorigenesis. We found that wild-type and $\mathrm{p} 38^{\mathrm{ki} / \mathrm{ki}} \mathrm{KRAS}$ mice contained a similar number of FSP-positive cells (Fig. 2D; Supplemental Fig. S2E,F), while p38 phosphorylation was reduced in $\mathrm{p} 38^{\mathrm{ki} / \mathrm{ki}} / \mathrm{KRAS}$ mice (Fig. 2D; Supplemental Fig. S2E). Next, we analyzed tumor lesions in mice that expressed a Kras transgene together with a floxed p38MAPK allele and Cre recombinase driven by a fibroblast-specific promoter (FSP1-Cre) and found a significant reduction in p38MAPK signaling (Fig. 2E). Of note, a lack of double staining for Cre and CD11b or F4/80 ruled out the possibility of a nonspecific FSP1-Cre expression in myeloid cells and monocytes/macrophages (Supplemental Fig. S2D). Thus, our finding suggested that fibroblasts were the main contributors to KRAS-driven activation of p38MAPK at the tumor site. Importantly, post-mortem analyses showed significant reductions in the number and size of tumor lesions in FSP1-Cre p $38^{f l / f 1}$ mice compared with FSP1-Cre p38 $8^{+/+}$mice (Fig. 2F). This finding suggested that stromal fibroblasts were the main contributors to p38MAPK activation at the tumor site, and this activation may be critical for initiating the series of events that promote KRAS-driven tumorigenesis.

\section{p38MAPK controls hyaluronic acid synthesis in fibroblasts to promote lung tumorigenesis}

p38MAPK is activated in the course of Kras-driven tumorigenesis, primarily at the periphery of the tumor site (Fig. 1C; Supplemental Fig. S1A); stromal fibroblasts appeared to be the main source of this activation (Fig. 2D). Importantly, genetic ablation of p38MAPK in stromal fibroblasts significantly reduced Kras-driven lung tumorigenesis (Fig. 2F). Next, we set out to investigate the molecular mechanism by which activation of p38MAPK in fibroblasts controls tumor growth. First, we conducted various coculture experiments to determine whether tumor-promoting activity relied on short- or long-distance cues produced by fibroblasts. KRAS tumor cells were seeded in the upper section of Boyden chambers to prevent direct contact with primary lung fibroblasts. We found no significant changes in tumor cell growth in cocultures with either wild-type or $p 38^{k i / k i}$ fibroblasts (Supplemental Fig. S3B). This indicated that the tumor-promoting fibroblast factors were most likely short-distance cues. To confirm this, we cocultured tumor cells directly with lung fibroblasts from cancer-free $\mathrm{p} 38^{+/+}$or $\mathrm{p} 38^{\mathrm{ki} / \mathrm{ki}}$ mice as three-dimensional (3D) spheroids. We found that cancer cell proliferation was significantly increased in cocultures with wild-type lung fibroblasts, but proliferation was reduced in cocultures with $p 38^{k i / k i}$ lung fibroblasts tested by cell number and the size of the spheres (Fig. 3A; Supplemental Fig. S3C). Furthermore, the tumors were significantly smaller when the mouse lung cancer cells were coinjected in nude mice with $p 38^{\mathrm{ki} / \mathrm{ki}}$ fibroblasts than when injected with $p 38^{+/+}$fibroblasts (Fig. 3B). These data strongly argued that p38 plays a key role in activating normal stromal fibroblasts to promote tumor formation. To unravel the mechanism, in further analyses, we focused on soluble cytokines, chemokines, and extracellular matrix (ECM) components.

Next, we purified lung fibroblasts from $\mathrm{p} 38^{+/+}$and p3 $8^{\mathrm{ki} / \mathrm{ki}}$ mice and carried out a microarray analysis, and differentially expressed genes were further reanalyzed with quantitative RT-PCR (qRT-PCR) in microdissected tumor lesions obtained from $\mathrm{p} 38^{\mathrm{ki} / \mathrm{ki}}$ and FSP1-Cre $\mathrm{p} 38^{\mathrm{fl} / \mathrm{fl}}$ mice. Among several differentially expressed genes, we found a consistent down-regulation of arginase 1 (Arg1), Arg2, and hyaluronan synthase 2 (Has2). Revalidation of the results by qRT-PCR revealed that the expression of Has2 (but not other family members: Has1 and Has3) (Fig. 3C) and the expression of both Arg1 and Arg2 were down-regulated in $\mathrm{p} 38^{\mathrm{ki} / \mathrm{ki}}$ cells (Supplemental Fig. S3D). Interestingly, Has2 (but not Has1 or Has3) was also highly up-regulated in a p38-dependent manner when lung fibroblasts were treated with TGF- $\beta$ (Supplemental Fig. S3D). Moreover, TGF- $\beta$ was not able to induce expression of CAF genes in $\mathrm{p} 38^{\mathrm{ki} / \mathrm{ki}}$ fibroblasts (Supplemental Fig. S3E). Importantly, overexpression of active MKK6 kinase was sufficient to induce Has2 and aSma expression (Supplemental Fig. S3F). These data strongly suggest that p38MAPK contributes to activation of HAS2 and potentially to the CAF phenotype. As the arginase inhibitor did not significantly affect the tumor-promoting activity of stromal fibroblasts in 3D cultures (data not shown), we focused on the potential role of Has 2 in regulating p38-dependent tumorigenesis.

Has 2 is the main enzyme in the synthesis of hyaluronic acid or hyaluronan, a part of an ECM that, within the tumor microenvironment, promotes cancer progression (Okuda et al. 2012). First, we found that increased deposition of hyaluronan was significantly diminished in p38 $8^{k i / k i}$ tumor lesions from Kras mice on a $p 38^{k i / k i}$ background (Fig. 3D, top panels). We also found that hyaluronan deposition was significantly reduced in cancer lesions from FSP1-Cre/Kras mice on a $p 38^{f 1 / f 1}$ background 
A
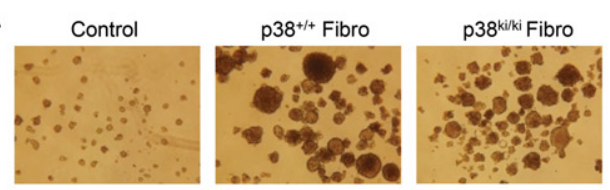

D
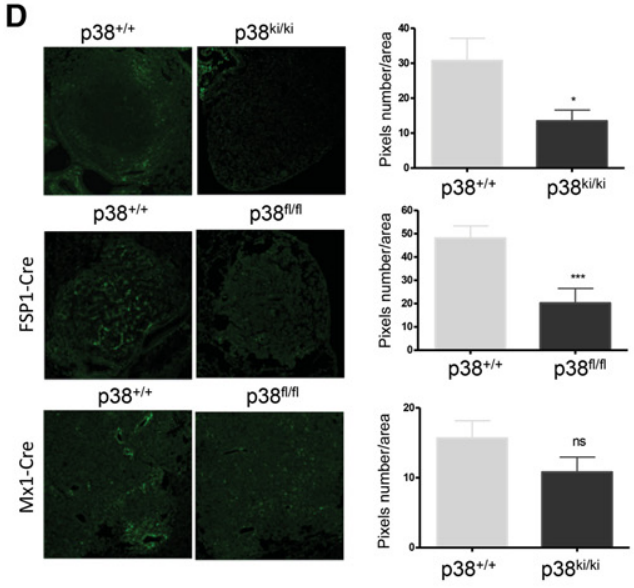

H

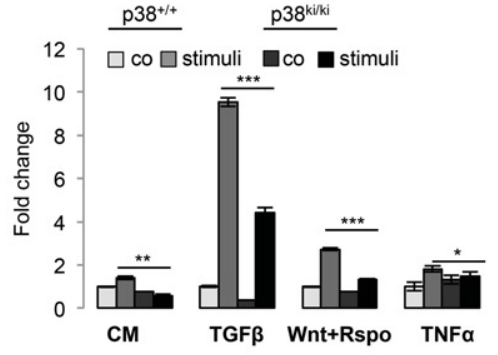

I

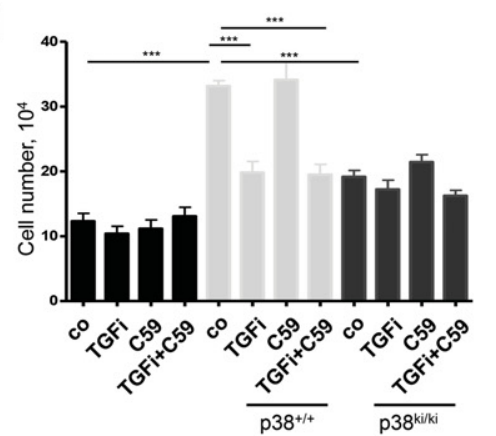

B
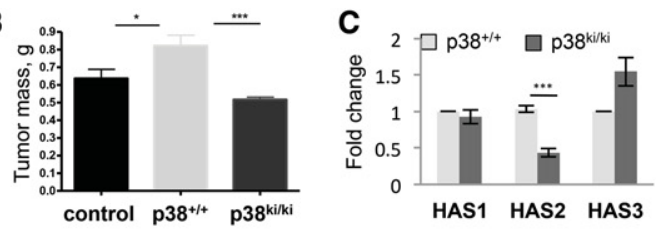

$F$

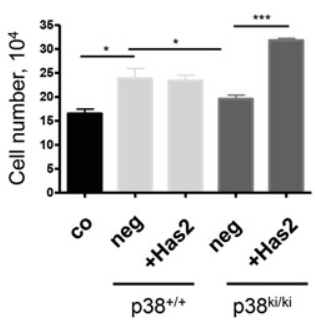

G
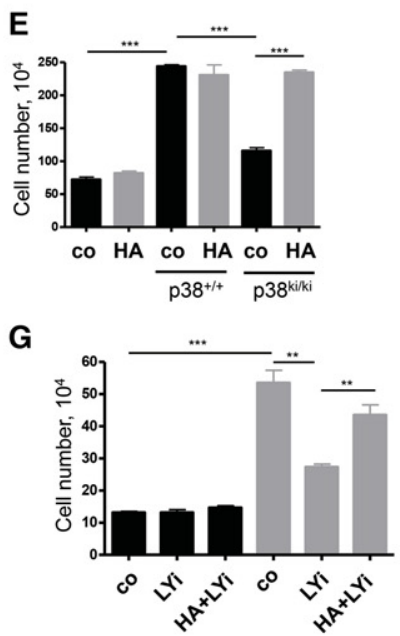

J

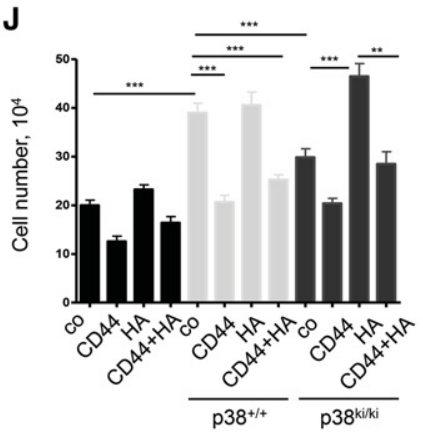

Figure 3. p38MAPK-dependent production of hyaluronan is required for lung tumorigenesis. $(A)$ Mouse lung cancer cells line established from lung tumors of KRAS mice were cocultured in spheroids either alone (control) or with primary lung fibroblasts isolated from tumorfree $\mathrm{p} 38^{+/+}$or $\mathrm{p} 38^{\mathrm{ki} / \mathrm{ki}}$ mice (fibro). Cells were grown for 6-8 d. Representative images of spheroids are shown. The number of cells was counted and is presented in the graph at the right as mean \pm SD. $n=6 .\left(^{*}\right) P<0.05 ;\left(^{* * *}\right) P<0.001$. (B) Primary KRAS/p53 ${ }^{-/-}$lung cancer cells were injected subcutaneously either alone (control) or with primary lung fibroblasts from $\mathrm{p} 38^{+/+}$or $\mathrm{p} 38^{\mathrm{ki} / \mathrm{ki}} \mathrm{mice}$. Tumors $(n=5)$ were weighed, and the average mass is presented as means $\left.\pm \mathrm{SD} .{ }^{*}\right) P<0.05$; $\left.{ }^{* * *}\right) P<0.001$. (C) Quantitative RT-PCR (qRT-PCR) analysis of gene expression in early-passage primary lung fibroblasts isolated from cancer-free $\mathrm{p} 38^{+/+}$or $\mathrm{p} 38^{\mathrm{ki} / \mathrm{ki}}$ mice. $n=4$. Mean $\pm \mathrm{SD}$. $\left(^{* * *}\right) P<$ 0.001. (D) Analysis of hyaluronan deposition detected by HABP staining in KRAS lung tumors in $\mathrm{p} 38^{+/+}$or $\mathrm{p} 38^{\mathrm{ki} / \mathrm{ki}}($ top $)$, $\mathrm{p} 38^{+/+}$or $\mathrm{p} 38^{\mathrm{fl} / \mathrm{fl}} \mathrm{FSP} 1-C r e\left(\right.$ middle), or $\mathrm{p} 38^{+/+}$or $\mathrm{p} 38^{\mathrm{f} / \mathrm{fl}} \mathrm{Mx} 1-\mathrm{Cre}($ bottom) mice. Quantification of HABP staining intensity is presented as the mean of the threshold ratio to the tumor area \pm SD. $n=9$. $\left({ }^{*}\right) P<0.05 ;\left(^{* * *}\right) P<0.001$; (ns) nonsignificant. (E) The cell numbers from desegregated spheroids of mouse lung cancer cells cocultured without or with $\mathrm{p} 38^{+/+}$or $\mathrm{p} 38^{\mathrm{ki} / \mathrm{ki}}$ lung fibroblasts. $n=3$ triplicates. Cells were either left untreated (co) or grown with high-molecular-weight hyaluronic acid (HA). Means \pm SD. $(* * *) P<0.001$. $(F)$ Primary lung fibroblasts isolated from tumor-free $\mathrm{p} 38^{+/+}$or $\mathrm{p} 38^{\mathrm{ki} / \mathrm{ki}}$ mice were transfected with a plasmid encoding hyaluronan synthase 2 (Has2)-GFP. Sorted GFP-positive cells were subjected to coculture as spheroids with KRAS/p53 ${ }^{-/-}$mouse lung cancer cells. Cells plated without fibroblasts are indicated by black bars. Cell growth was calculated and is presented as means \pm SD. $n=4 .(*) P<0.05 ;\left(^{* * *}\right) P<0.001$. $(G)$ The cell numbers from desegregated spheroids of mouse lung cancer cells cocultured with $\mathrm{p} 38^{+/+}$fibroblasts $(n=3)$ grown in the presence of $\mathrm{p} 38$ inhibitor LY2228820 or high-molecular-weight hyaluronan (HMW-HA [HA]). $(H)$ The qRT-PCR analysis of Has2 mRNA levels in p38 ${ }^{+/+}$and $\mathrm{p} 38^{\mathrm{ki} / \mathrm{ki}}$ primary lung fibroblasts in nonstimulated condition $(\mathrm{co})$ and in response to conditioned medium from KRAS/p53 ${ }^{-/-}$lung cancer cells $(\mathrm{CM})$, TGF $\beta 1$, and a mixture of Wnt3a and R-spondin or TNFa. Data are shown as a fold change compared with control p38 ${ }^{+/+}$fibroblasts, set as 1 . Data are shown as mean \pm SD. $n=3 .\left({ }^{*}\right) P<0.05 ;\left({ }^{* *}\right) P<0.01 ;\left({ }^{* *}\right) P<0.001$. (I) The cell numbers from desegregated spheroids of mouse lung cancer cells cocultured without (black) or with $\mathrm{p} 38^{+/+}$(light gray) or p38 $8^{\mathrm{ki} / \mathrm{ki}}$ (dark gray) primary mouse lung fibroblasts. Cells were untreated (co) or grown in the presence of TGF $\beta 1$ pathway inhibitor SB431542 (TGFi), porcupine inhibitor C59, or both inhibitors together (TGFi + C59). Data are shown as means \pm SD. $n=3 .\left(^{* * *}\right) P<0.001$. $(J)$ The cell numbers from desegregated spheroids of mouse lung cancer cells cocultured without (black) or with $\mathrm{p} 38^{+/+}$(light gray) or $\mathrm{p} 38^{\mathrm{ki} / \mathrm{ki}}$ (dark gray) primary mouse lung fibroblasts. Cells were untreated (co) or grown in the presence of anti-CD44 antibody with and without the inclusion of hyaluronan. Data are shown as mean \pm SD. $\left.n=3 .\left(^{* *}\right) P<0.01 ;{ }^{* * *}\right) P<0.001$. 
(Fig. 3D, middle panels) but not from $M x$-Cre/Kras mice (Fig. 3D, bottom panels). This result supported the notion that specific p38 activation in stromal fibroblasts controlled hyaluronan deposition at the tumor site.

Next, we investigated whether the hyaluronan production controlled by p38 kinase was essential for tumor growth in vitro. Lung tumor cells were cocultured with p38 $8^{+/+}$and $p 38^{\mathrm{ki} / \mathrm{ki}}$ lung fibroblasts in the presence of high-molecular-weight hyaluronan (HMW-HA), and we found that it was sufficient to fully restore the ability of p38 ${ }^{k i / k i}$ fibroblasts to promote tumor cell growth in vitro in $3 \mathrm{D}$ coculture (Fig. 3E). In addition, overexpression of HAS2 completely restored the ability of $p 38^{\mathrm{ki} / \mathrm{ki}}$ lung fibroblasts to support tumor growth (Fig. 3F). Next, pharmacological inhibition of p38MAPK blocked the ability of fibroblasts to promote tumor growth in $3 \mathrm{D}$ cultures and in vivo; the effect was completely reversed by inclusion of HMW-HA (Fig. 3G; Supplemental Fig. S3G). These data strongly argue that p38MAPK-dependent hyaluronan synthesis is critical for stromal fibroblasts to promote lung cancer growth.

Next, we analyzed factors that might be responsible for Has2 induction and hyaluronan accumulation in stromal fibroblasts. We found that conditioned medium from lung cancer cells (Fig. $3 \mathrm{H}$ ) could activate Has 2 expression and hyaluronan accumulation (Supplemental Fig. S3H) in wild-type, but not $p 38^{k i / k i}$, lung fibroblasts. Similar results were obtained in coculture experiments with lung cancer tumor cells growing in hanging inserts (Supplemental Fig. S3I). We further tested different cytokines and found that TGF- $\beta$ and, to lesser extent, Wnt activators and TNFa could induce Has2 expression and hyaluronan deposition in a p38MAPK-dependent manner (Fig. 3H; Supplemental Fig. S3H). Importantly, inhibiting the TGF- $\beta$ pathway with an ALK5 inhibitor (SB431542) significantly reversed the growth-promoting activity of wild-type, but not $p 38^{\mathrm{ki} / \mathrm{ki}}$, lung fibroblasts in $3 \mathrm{D}$ sphere coculture assays (Fig. 3I). Furthermore, anti-CD44 inhibitory antibody fully blocked the growth-promoting activity of wild-type fibroblasts and completely reversed the resque effect of hyaluronan in $p 38^{\mathrm{ki} / \mathrm{ki}}$ lung fibroblasts (Fig. 3J).

\section{Hyaluronan synthesis is required for primary human lung cancer growth}

To address the question of whether the described mechanism is applicable to human cells, we established several primary human lung cancer cell lines based on the material acquired from patients during surgery. Similar to our results with mouse lung cancer cells, the wild-type primary mouse lung fibroblasts efficiently increased the growth of human lung cancer cells in $3 \mathrm{D}$ sphere conditions in a p38-dependent manner (Fig. 4A; Supplemental Fig. S4A). The tumor-promoting role of $\mathrm{p} 38$ was further validated after injecting a mixture of either wild-type and $\mathrm{p} 38^{\mathrm{ki} / \mathrm{ki}}$ fibroblasts or human lung CAFs and p38shRNA-depleted CAFs with primary human lung cancer cells into nude mice (Fig. 4B). Consistent with these observations, the p38 chemical inhibitor LY2228820 also prevented wild- type lung fibroblasts from promoting human cancer cell growth (Fig. 4C).

To determine whether hyaluronan synthesis was required for the growth of primary human cancer cells, we supplemented the culture medium with HMW-HA. The presence of HMW-HA significantly reversed the growth inhibitory effects of both the p38 inhibitor LY2228820 (Fig. 4C; Supplemental Fig. S4B) and $p 38^{k i / k i}$ lung fibroblasts (Fig. 4D). To confirm the role of hyaluronan in tumor-promoting activity, we inhibited hyaluronan synthesis with the chemical inhibitor 4-methylumbelliferone (4MU), which was reported to block hyaluronan deposition efficiently (Kakizaki et al. 2004; Kultti et al. 2009). We found that $4 \mathrm{MU}$ inhibited the growth of both mouse (Fig. 4E) and human T27 (Fig. 4F) and T24 (Supplemental Fig. S4B) primary lung cancer cells in 3D cocultures with mouse lung fibroblasts. Please note that $4 \mathrm{MU}$ also inhibited the activation of CAF genes in response to TGF- $\beta$ (Supplemental Fig. S4C); both LY2228820 and $4 \mathrm{MU}$ prevented TGF- $\beta$-dependent accumulation of hyaluronan in primary lung fibroblasts (Supplemental Fig. S4D). We further found that the inhibitor of TGF- $\beta$ significantly blocked the tumor-promoting ability of wild-type fibroblasts to support human lung cancer growth in $3 \mathrm{D}$ assays (Fig. 4G). Overall, our results confirmed the role of the p38-hyaluronan axis in regulating primary human lung cancer growth in vitro.

\section{p38MAPK-hyaluronan-dependent signaling supports human CAF activation}

The conversion of stromal fibroblasts into CAFs is a key step in reprogramming the normal microenvironment to create a cancer niche. Thus, we asked whether the p38MAPK pathway might play a role in this process. First, we assessed the role of p38MAPK in TGF- $\beta$-mediated human lung fibroblast activation and found that TGF- $\beta$ upregulated mRNA levels of the CAF marker aSMA in a p38-dependent manner (Fig. 5A,B; Supplemental Fig. S5E,F). Similarly, in human lung CAFs, inhibition of p38MAPK or genetic ablation of p38 expression induced a significant reduction in aSMA mRNA levels (Fig. 5C; Supplemental Fig. S5G) without affecting fibroblast mitochondrial activity (Supplemental Fig. S5A,B). Moreover, in human lung fibroblast cells, TGF- $\beta$-dependent increases in the levels of tenascin $\mathrm{C}$, fibronectin, collagen $1 \mathrm{~A} 1$, and lysyl oxidase mRNAs were dependent on p38MAPK activity (Supplemental Fig. S5C). Additionally, in human lung CAF cells, p38 inhibition repressed fibronectin and tenascin C mRNA levels (Supplemental Fig. S5D). Taken together, these data suggested that p38 governed CAF-dependent ECM organization, and this activity could be critical in supporting tumor growth.

To assess the role of CAFs during tumor growth, we investigated the potential role of p38MAPK in establishing the physical characteristics of CAF-derived ECM. We used orthogonal light to visualize Picrosirius red-stained, CAF-derived ECM and found that inhibiting p38 activity with two different inhibitors (Fig. 5D,E) or genetic ablation of p38 expression in CAFs (Supplemental Fig. S5H,I) 

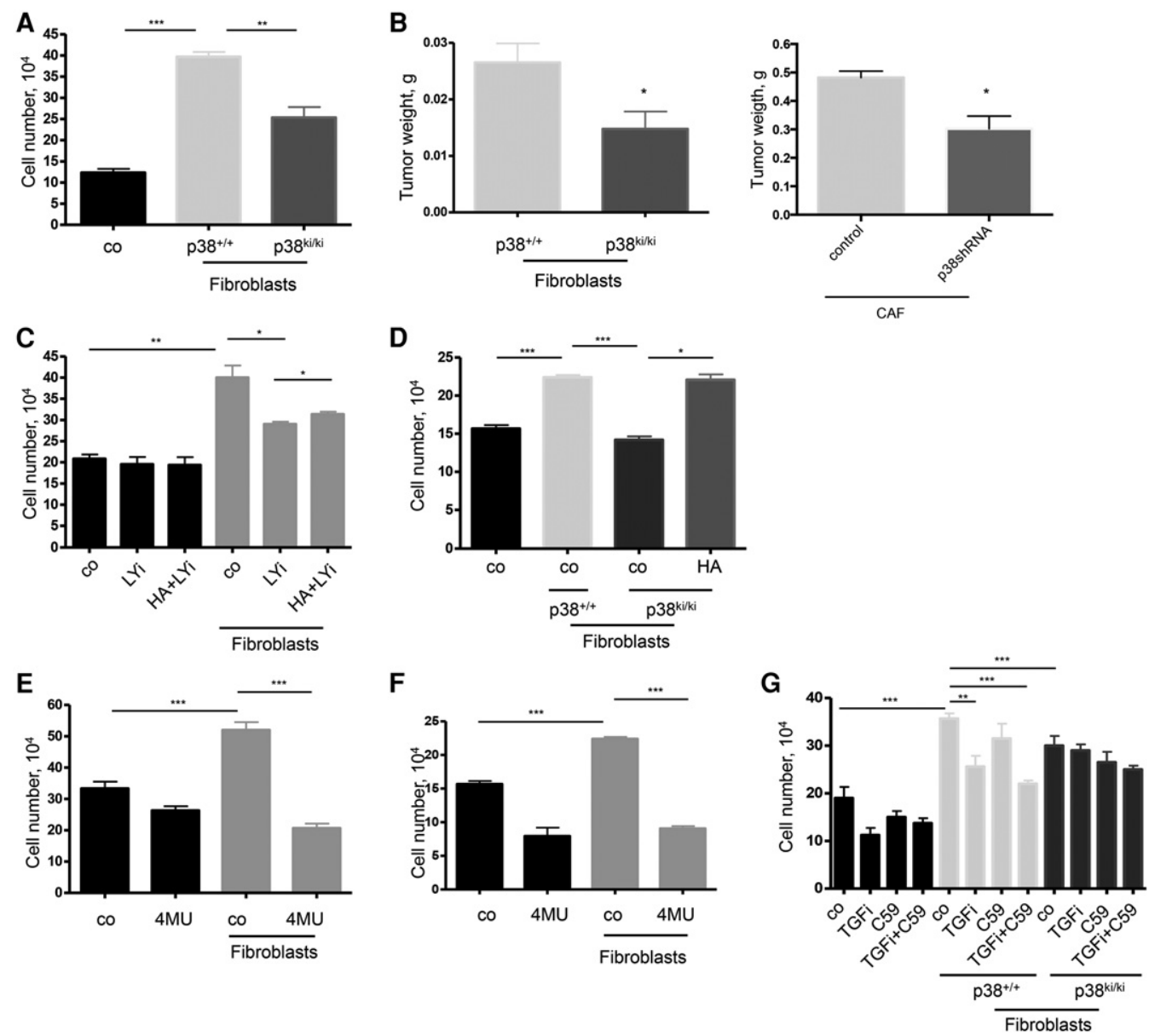

Figure 4. Inhibition of hyaluronan synthesis blocks mouse and human lung cancer cell growth. $(A)$ The cell numbers from desegregated spheroids of patient-derived T27 primary human lung cancer cells cocultured with primary mouse lung fibroblasts from p38 ${ }^{+/+}$or $\mathrm{p} 38^{\mathrm{ki} / \mathrm{ki}}$ mice. Data are shown as mean \pm SD. $n=3 .\left(^{* *}\right) P<0.01 ;\left(^{* * *}\right) P<0.001$. $(B)$ Tumor analysis after subcutaneous injection of patient-derived $\mathrm{T} 27$ primary human lung cancer cells together with primary lung fibroblasts from $\mathrm{p} 38^{+/+}$or p38 $8^{\mathrm{ki} / \mathrm{ki}}$ mice (left) or control and p38 shRNAdepleted CAFs $\left(\right.$ right). T27 cells injected alone did not form tumors for the analyzed period. $n=4$. Mean \pm SD. $\left(^{*}\right) P<0.05$. $(C)$ The cell numbers from desegregated spheroids of patient-derived T27 primary human lung cancer cells cultured without (black) or with (gray) primary wild-type mouse lung fibroblasts without any treatment (co), in the presence of LY2228820 (LYi), or in combination with HMW-HA (HA + LYi). $n=3$. Mean \pm SD. $\left.\left({ }^{*}\right) P<0.05 ;{ }^{* *}\right) P<0.01$. $(D)$ The cell numbers from desegregated spheroids of patient-derived T27 primary human lung cancer cells cultured alone (black bars; co) or cocultured with $\mathrm{p} 38^{+/+}$or $\mathrm{p} 38^{\mathrm{ki} / \mathrm{ki}}$ mouse lung fibroblasts supplemented with HMW-HA $(\mathrm{HA}) . n=3$. Mean \pm SD. $\left({ }^{*}\right) P<0.05 ;\left(^{* * *}\right) P<0.001$. $(E, F)$ Mouse lung cancer cells $(E)$ or T27 primary human lung cancer cells $(F)$ cultured as spheroids without (black bars) or with (gray bars) primary mouse lung fibroblasts. Cells were untreated (co) or grown in the presence of 4 methylumbelliferone (4MU). $n=3$. Mean \pm SD. $\left({ }^{* * *}\right) P<0.001$. $(G)$ The cell numbers from desegregated spheroids of patient-derived T27 primary human lung cancer cells cultured without (black) or with $\mathrm{p} 38^{+/+}$(light gray) or p38 $8^{\mathrm{ki} / \mathrm{ki}}$ (dark gray) primary mouse lung fibroblasts. Cells were untreated (co) or grown in the presence of TGF $\beta 1$ inhibitor SB431542 (TGFi), porcupine inhibitor C59, or both inhibitors together (TGFi + C59). $n=3$. Mean \pm SD. $\left(^{* *}\right) P<0.01 ;\left(^{* * *}\right) P<0.001$.

caused a reduction in the deposition of collagen-crosslinked fibers. Conversely, TGF- $\beta$-activated fibroblasts showed a p38-dependent increase in collagen cross-linking compared with the vehicle control (Fig. 5F,G). Taken together, these data suggested that p38MAPK signaling was essential for fibroblast activation in lung cancer and that inhibition of this signaling pathway could reduce ECM remodeling.

Next, we investigated whether p38 in activated fibroblasts played a role in ECM remodeling to promote lung cancer cell proliferation. The human lung cancer cell lines bearing different mutations-A427, A549, CALU1, and H838-were seeded on a CAF-derived ECM and stained for PCNA, a cell proliferation marker. We found that inhibition of p38MAPK activity or genetic ablation of p38 in CAFs during ECM remodeling affected the biochemical properties of the derived matrix and altered the ability of the ECM to stimulate tumor cell proliferation (Fig. 5H,I; Supplemental Fig. S5J-O). Finally, in a tumor invasion assay with $3 \mathrm{D}$ spheroids cocultured with a collagen-rich matrix, we demonstrated that A427 tumor cell invasion was significantly reduced when p38 kinase 

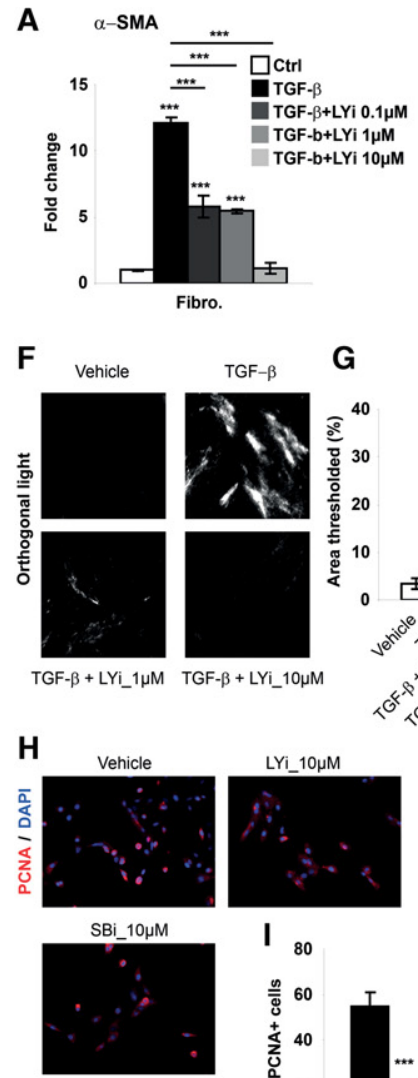

B $\quad$-SMA

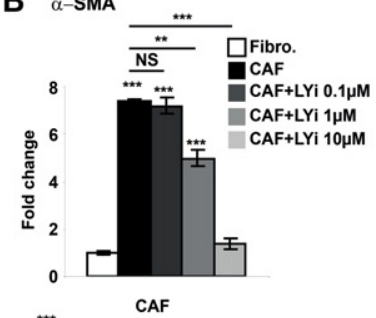

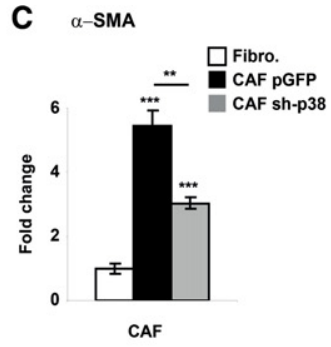

$J_{80}$

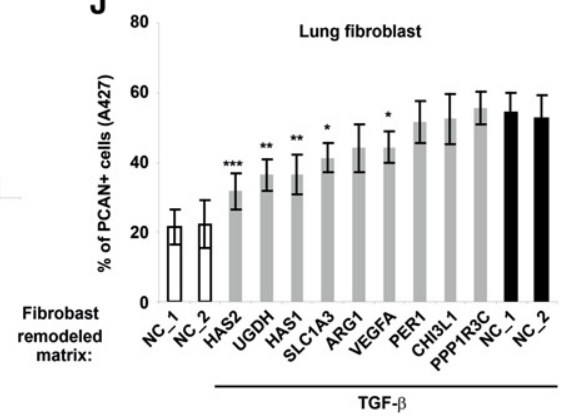

K

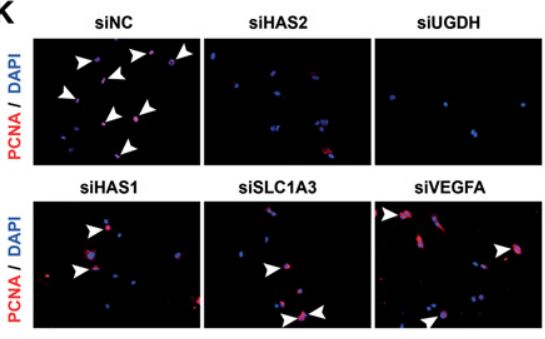

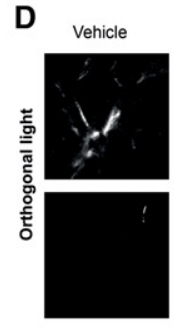

SBi_10 $10 \mathrm{M}$
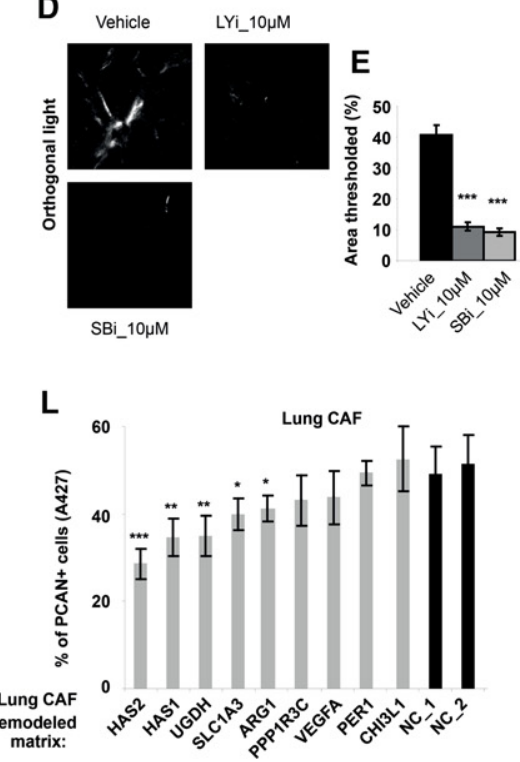

M

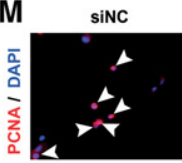

siUGDH

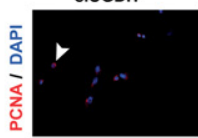

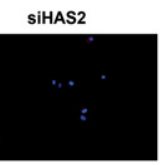

siSLC1A3

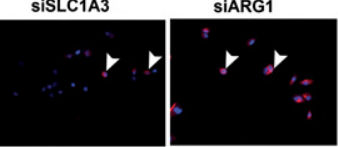

Figure 5. p38MAPK-hyaluronan-dependent signaling supports human CAF activation. $(A)$ Quantification of mRNA level of aSMA in human lung fibroblasts following $48 \mathrm{~h}$ of TGF- $\beta 1$ stimulation in the presence of inhibitor LY2228820. $n=3$. Mean \pm SD. (***) $P<0.001$. $(B)$ Quantification of mRNA level of aSMA in human lung CAFs in the presence of inhibitor LY22 for 48 h relative to human lung fibroblasts as control (Fibro). $n=3$. Mean \pm SD. $(* *) P<0.01 ;\left({ }^{* * *}\right) P<0.001 ;(N S)$ not significant. $(C)$ Quantification of mRNA levels of $\alpha$ SMA in human lung CAFs after genetic ablation of $\mathrm{p} 38$ relative to human lung fibroblasts as control (Fibro). $n=3 . \mathrm{Mean} \pm \mathrm{SD}$. $\left(^{* *}\right) P<0.01$; $\left({ }^{* * *}\right) P<$ 0.001. (D) Orthogonal light visualization of Picrosirus red coloration showing ECM remodeling by lung CAFs in the presence of LY or SB. $(E)$ Quantification of ECM remodeling shown in $D . n=3$. Mean \pm SD. $(F)$ Orthogonal light visualization of Picrosirus red coloration showing ECM remodeling by TGF $\beta 1$-stimulated lung fibroblasts in the presence of LY or SB. $(G)$ Quantification of ECM remodeling shown in $F$. $n=3$. Mean \pm SD. $\left({ }^{*}\right) P<0.05 ;\left(^{* *}\right) P<0.001 .(H)$ Representative image of PCNA staining of A427 tumor cells plated on CAF-derived matrix in the presence of LY or SB. (I) Quantification of PCNA staining shown in $H . n=3$. Mean \pm SD. $\left(^{* * *}\right) P<0.001$. $(J)$ Quantification of PCNApositive A427 tumor cells plated on TGF $\beta 1$-activated fibroblast-derived matrix following siRNA transfection. $n=3$. Mean \pm SD. $\left({ }^{*}\right) P<$ 0.05 ; $\left.\left({ }^{* *}\right) P<0.01 ;{ }^{* * *}\right) P<0.001$. $(K)$ Representative images of quantification shown in $J$. $(L)$ Quantification of PCNA-positive A427 tumor cells plated on lung CAF-derived matrix following siRNA transfection. $n=3$. Mean \pm SD. $\left({ }^{*}\right) P<0.05 ;\left(^{* *}\right) P<0.01 ;\left({ }^{* * *}\right) P<0.001$. $(M)$ Representative images of quantification shown in $L$.

was inhibited or specifically ablated in CAF cells (Supplemental Fig. S5P-S). Taken together, these results demonstrated that p38-dependent signaling governed fibroblast activation and led to the development of a protumorigenic ECM.

To understand the role of the p38-hyaluronan axis in protumorigenic fibroblast activation, we used siRNAs to knock down gene expression in fibroblasts and tested their function in TGF- $\beta$-dependent matrix remodeling. We silenced the expression of p38MAPK, Has2, and Arg1 in addition to several other genes that were differentially expressed in wild-type and $p 38^{k i / k i}$ lung fibroblasts (Fig. 5J-M). We also included a positive control for hyaluronan synthesis, UDP-glucose 6-dehydrogenase $(U G D H)$, to confirm or rule out the potential role of hyaluronan in matrix remodeling and cancer cell proliferation. Both TGF- $\beta$-activated and CAF-derived matrices were produced after siRNA depletion of the indicated genes. After plating A427 lung cancer cells on each matrix, we analyzed cancer cell proliferation. Among the tested genes, we found that two HAS family member genes (HAS1 and HAS2) and UGDH significantly regulated matrix-dependent tumor cell proliferation. This result confirmed that hyaluronan synthesis was an essential component of protumorigenic ECM produced by fibroblasts. 


\section{HAS2 drives p38-dependent protumorigenic CAF activities}

Next, we turned to an analysis of the role of p38MAPK in HAS2 expression and hyaluronan induction in human cells. We found that conditioned medium from a human lung cancer cell line, A427, efficiently induced both HAS2 expression and hyaluronan accumulation in human lung fibroblasts in a p38MAPK-dependent manner (Fig. $6 \mathrm{~A}-\mathrm{D})$. We tested a panel of different cytokines and found that both TGF- $\beta$ and TNF- $\alpha$ could efficiently induce p38dependent HAS2 expression and hyaluronan production. Furthermore, the p38MAPK inhibitor efficiently downregulated both HAS2 expression and hyaluronan production in human lung CAFs (Fig. 6A-D).

We next investigated the potential anti-tumor activities of both p38MAPK and hyaluronan synthesis inhibi- tors. We studied both the invasive potential and proliferation properties of patient-derived primary lung cancer cells in vitro (designated as T24 and T27 cells). Spheroids comprised of cancer cells were embedded in a collagen I gel rich in laminins. We found that inhibition of p38 activity (with two different inhibitors) or hyaluronan synthesis (with 4MU) significantly reduced the invasiveness of T24 and T27 tumor cells in vitro (Fig. $6 \mathrm{E}, \mathrm{F})$. Under these experimental conditions, targeting p38MAPK or hyaluronan synthesis also led to reduced PCNA staining of E-cadherin-positive cells within the spheroids (Fig. 6G,H). This finding indicated that the inhibitors specifically affected epithelial tumor cell proliferation. Taken together, these data demonstrated that the p38MAPK and hyaluronan synthesis signaling pathways were critical for primary human lung cancer growth in vitro.
A
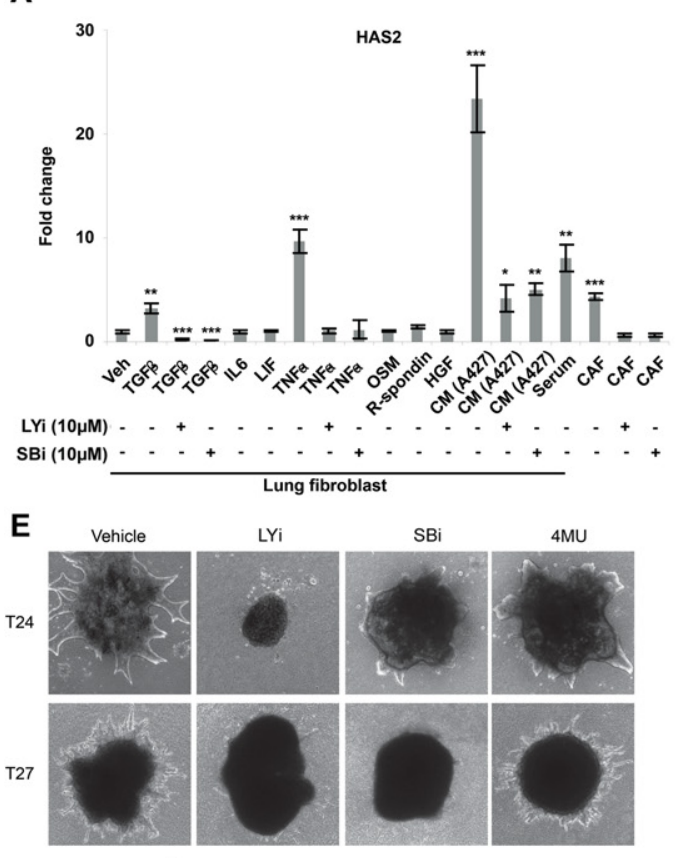

F 0.8

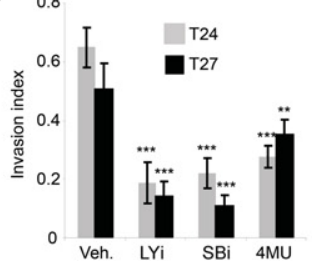

B

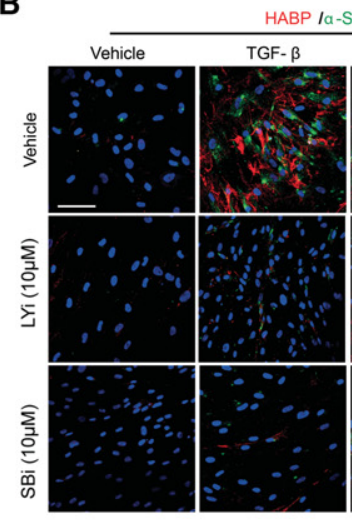

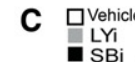
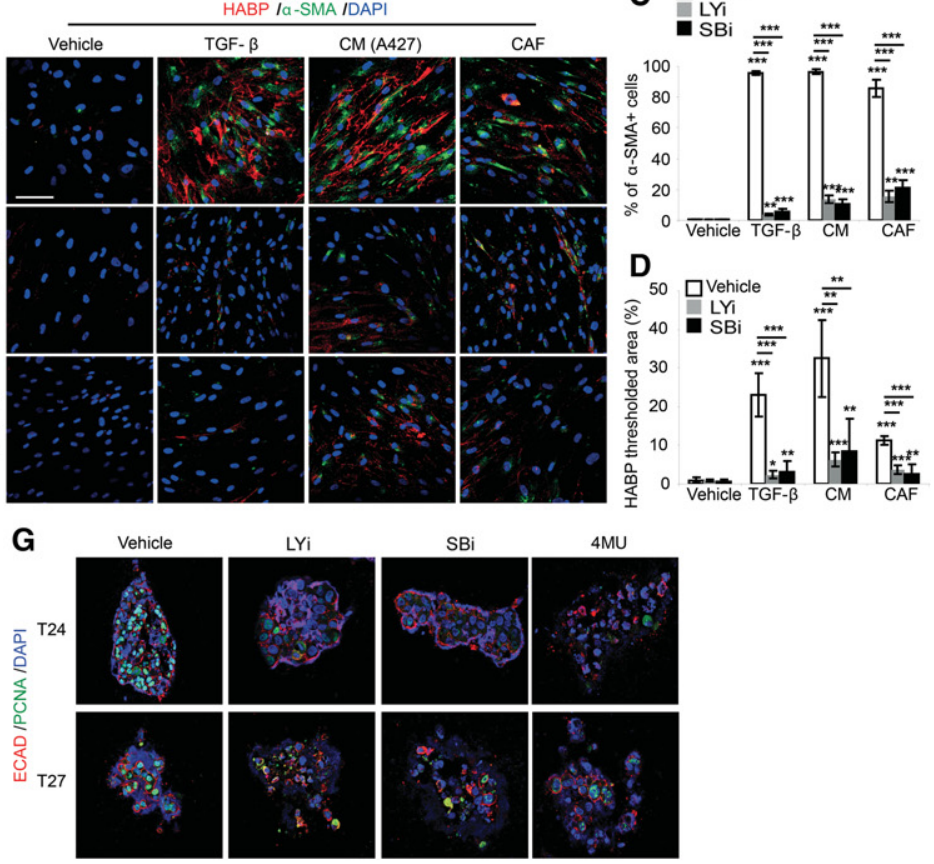

H

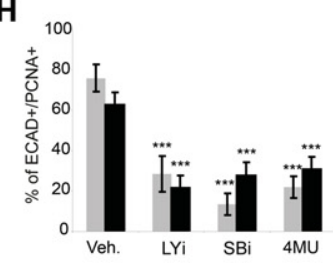

Figure 6. HAS2 drives p38-dependent protumorigenic CAF activities. (A) Quantification of HAS2 mRNA in human lung fibroblasts following cytokine or tumor cell conditioned medium stimulation in the presence or absence of p38MAPK inhibitors (LY or SB). Expression in the control group (fibroblast vehicle) was assumed to be 1 , to which relevant samples were compared. Data are means \pm SD. $n=3$. $\left({ }^{*}\right) P<$ $\left.\left.0.05 ;{ }^{* *}\right) P<0.01 ;{ }^{* * *}\right) P<0.001$. (B) Representative images of fibroblast activation (aSMA ${ }^{+}$cells) and hyaluronan deposition (HABP labelling) in the ECM of fibroblasts exposed to TGF $\beta$ or A427 conditioned medium. Bar, $50 \mu \mathrm{m}$. (C) Quantification of aSMA ${ }^{+}$cells shown in $B$. Mean \pm SD. $n=3$. $\left(^{* * *}\right) P<0.001$. $(D)$ Quantification of HABP staining shown in $B$. Mean \pm SD. $n=3 .\left(^{* *}\right) P<0.01 ;\left({ }^{* * *}\right) P<0.001$. $(E)$ Representative images of PDTX (T24 and T27) spheroids in the presence of LY, SB, or 4MU inhibitors. (F) Quantification of the PDTX tumor cell invasion shown in E. (G) Representative images of PDTX spheroid cells stained for E-cadherin (red), PCNA (green), and DAPI (blue). (H) Quantification of PCNA-positive and E-cadherin-positive cells from $G$. Mean \pm SD. $n=3 .\left(^{* * *}\right) P<0.001$. 
Inhibiting p38MAPK and hyaluronan synthesis blocks lung cancer growth in vivo

Inhibition of the p38-hyaluronan pathway could efficiently reduce the tumor-promoting activity of stromal fibroblasts in vitro. Next, we investigated whether a similar effect could be detected in vivo. First, we evaluated the effects of the p38MAPK inhibitor LY2228820 and the hyaluronan synthesis inhibitor 4MU on cancer growth in a mouse model of KRAS-induced lung tumorigenesis. We found that treating mice with either LY2228820 or 4MU significantly reduced the mouse lung tumor burden (Fig. 7A,B, left panels). Furthermore, both inhibitors significantly reduced hyaluronan deposition at the tumor site (Fig. 7A,B, right panels).

Next, we tested these findings in primary human lung cancer. First, we established an orthotopic tumor model by growing primary human lung tumor cells into the lungs of NSG mice to evaluate growth in a natural microenvironment. To facilitate the analysis of tumor growth, we engineered patient-derived human lung cancer cells to express secreted luciferase. We confirmed that the luciferase activity detected in the blood of transplanted animals correlated well with tumor progression in the lungs. Both LY2228820 (Fig. 7C) and 4MU (Fig. 7E) significantly reduced the tumor burden of orthotopically transplanted primary human lung cancer cells, based on both the luciferase activity in the blood and the tumor area. Furthermore, we observed a significant reduction in hyaluronan deposition at the tumor site in the presence of either inhibitor (Fig. 7D,F). These data strongly argued that inhibitors of p38MAPK and hyaluronan synthesis could efficiently block the growth of primary human lung cancer in vivo.

\section{Discussion}

Lung cancer is among the top three most frequent cancers and the leading cause of cancer-related mortality worldwide (Zhang et al. 2014). It is becoming clear that the
A

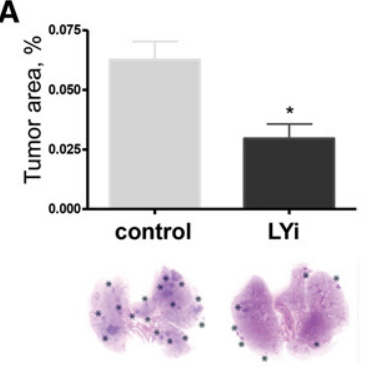

C

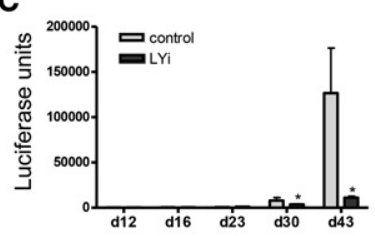

\section{D}

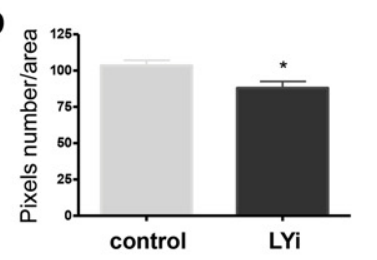

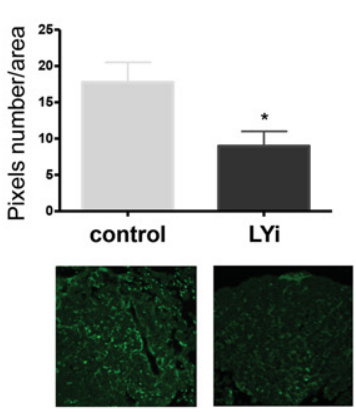

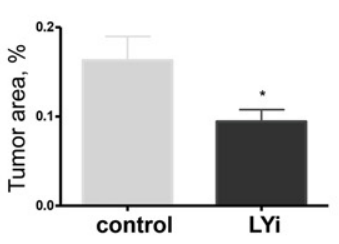

control

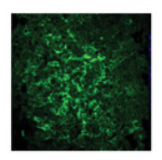

B
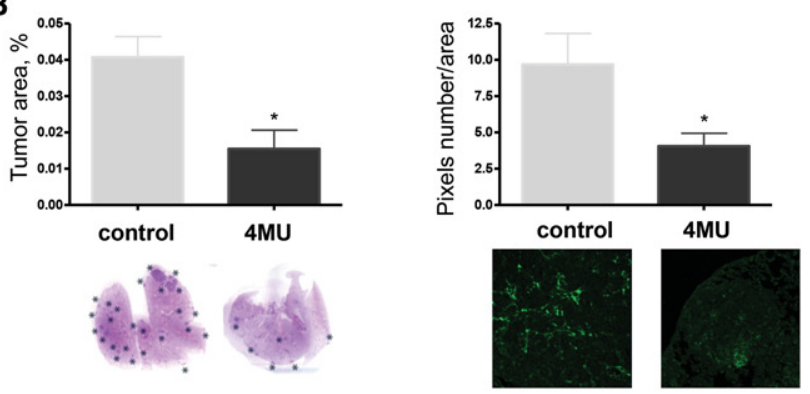

E
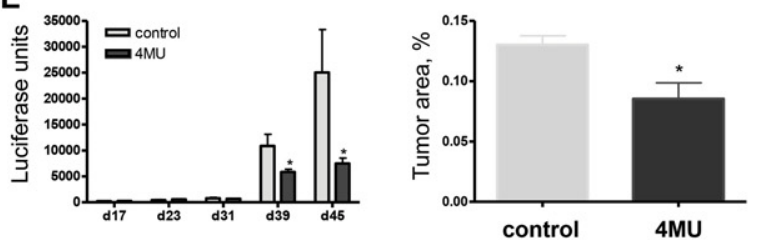

$\mathbf{F}$

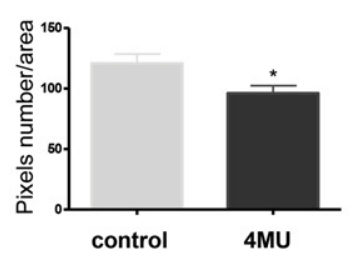

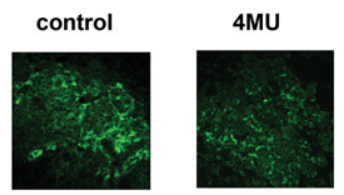

Figure 7. Inhibiting p38MAPK and hyaluronan synthesis blocks lung cancer growth in vivo. Five-week-old KRAS mice (six mice per group) were either treated with vehicle control, injected intraperitoneally with $250 \mu \mathrm{g}$ of LY2228820 (LYi) per mouse twice per week for $5 \mathrm{wk}(A)$, or treated with $4 \mathrm{MU}$ in the drinking water and gavaging twice per week $(B)$. Representative images of the lung section show relative tumor area as the percentage relative to total lung area; asterisks indicate lesions. Sections were stained with HABP, and one representative image is shown. Analysis of intensity staining was quantified as the mean of the pixel number per area ratio and is presented as graphs. $n=8 \pm$ SD. $\left({ }^{*}\right) P<0.05$. Primary T27 human lung cancer cells expressing secreted luciferase were injected intravenously into NSG mice to develop lung lesions. Sixteen days to $20 \mathrm{~d}$ after injection, mice were either left untreated (control), injected with LY2228820 (LYi) twice per week until day $43(C, D)$, treated with $4 \mathrm{MU}$ in the drinking water and gavaging until day $45(E, F) .(C, E)$ Mice were bled once per week to measure luciferase readings (left graph) $(n=5)$, and relative tumor area was measured on hematoxylin/eosin-stained slides (right graph) $(n=5)$. Hyaluronan deposition was analyzed by HABP staining (representative images are shown). The intensity was quantified as the mean of the pixel number per area ratio $(n=16)$ and is presented as graphs. Mean \pm SD. $\left({ }^{*}\right) P<0.05$. 
most effective approach for treating lung cancer requires therapies that target both tumor cells and the tumor microenvironment. In this respect, stromal fibroblasts could be attractive targets because they are known to provide additional signals to support tumor growth, survival, and drug resistance (Bremnes et al. 2011; El-Nikhely et al. 2012). Unfortunately, no treatment option exists that successfully targets this component of the tumor microenvironment. Here, we propose that targeting the p38-hyaluronan pathway could provide a clinically relevant option for blocking the tumor-promoting activities of the stroma.

p38MAPK has been implicated previously in regulating lung homeostasis (Brancho et al. 2003; Hui et al. 2007; Ventura et al. 2007). Deleting p38MAPK in lung epithelium resulted in increased proliferation and defective differentiation of lung progenitors, which correlated with elevated expression of EGFR. Consistent with those results, a conditional p38 deletion in Kras-bearing epithelial cells facilitated lung tumorigenesis. Those data supported the notion that reducing the levels of $\mathrm{p} 38 \mathrm{MAPK}$ in cancer cells could enhance tumorigenesis; thus, p38MAPK could play the role of a tumor suppressor. In the present study, we confirmed that targeting p38 specifically in cancer cells promoted tumor growth (Fig. 1G). Much to our surprise, however, the systemic inactivation of p38MAPK appeared to have a completely opposite, tumor-suppressive function (Figs. 1E, 2F). Our study revealed this critical role for $\mathrm{p} 38 \mathrm{MAPK}$ as a tumor promoter in the lung cancer microenvironment.

Noncancer cells can account for as much as $90 \%$ of a tumor cell mass. Moreover, there is a strong correlation between an increasing amount of stroma with cancer malignancy and patient prognosis, which makes analysis of the tumor microenvironment clinically relevant (Bremnes et al. 2011). Fibroblasts that are recruited into tumors (CAFs) are the main components of the stroma of many solid cancers, including carcinomas (Shiga et al. 2015; Gascard and Tlsty 2016). However, the nature of the initial signals that instigate the creation of the tumor niche is less well established. Here, we provide evidence that $338 \mathrm{MAPK}$ could play an important role in subverting the normally repressive stroma to become protumorigenic. We showed that lung fibroblasts from cancer-free mice could be rapidly reprogrammed to sustain tumor growth. This process was characterized by $\mathrm{p} 38$-dependent activation of Has 2 expression in fibroblasts and the subsequent accumulation of hyaluronan. These early stages of p38MAPK activation and hyaluronan production were critical for fibroblast reprogramming into CAFs. The inhibition or the lack of CAFs in turn attenuated lung cancer cell proliferation in vitro and in vivo.

Hyaluronan is a major component of the ECM (Toole 2004). Hyaluronan is specifically enriched around proliferating and migrating cells in rapidly remodeling tissues, including cancer. Hyaluronan has key regulatory roles in tissue homeostasis and possesses signaling properties through its interaction with cell surface receptors, such as CD44 and RHAMM (Toole 2004). Most malignant tumors contain elevated amounts of CD44, and many reports showed that CD44 is abundant on the surface of cancer stem cells (Yan et al. 2015). The presence of hyaluronan could promote clustering of EGFR and CD44, which form a functional unit on the membrane of tumor cells that could be specifically relevant to lung cancer (Meran et al. 2011). Consistent with these results, we found that stromal fibroblasts promote p38-hyaluronandependent cancer cell growth through CD44 (Fig. 3J).

Here, we found that, in stromal fibroblasts, HAS2 expression was specifically regulated in a p38MAPK-dependent manner in response to multiple factors, including TGF- $\beta$, Wnt, and TNF- $\alpha$. HAS2 is involved in the epithelial-mesenchymal transition during embryonic cardiac cushion morphogenesis (Camenisch et al. 2000) and also increased during malignant progression. Elevated HAS2 levels were observed specifically in nests of cancer cells and at the invading edges of breast carcinomas (Toole 2001). Furthermore, overexpression of HAS2 in the epithelium induced the transition of epithelial cells to a more fibroblastic, migratory phenotype and enhanced anchorageindependent growth in soft agar (Li and Heldin 2001; Zoltan-Jones et al. 2003). In our setting, overexpression of HAS2 or inclusion of HMW-HA fully reversed the tumor-suppressive properties of normal fibroblasts (Figs. 3E,F, 4C,D). Our results are consistent with those from other studies, which showed, both in vivo and in vitro, that ectopic expression of HAS proteins (and consequent increases in hyaluronan synthesis) promoted tumor progression (Koyama et al. 2007, 2008).

The activation of p38MAPK and accumulation of hyaluronan in lung tumors could have important therapeutic implications. The fact that lung cancer depends on supporting stromal cells implies that the p38-hyaluronan axis is an attractive target for intervention. Here, we showed the importance of hyaluronan in establishing a cancer niche at early stages of tumorigenesis. However, increasing evidence has demonstrated that both CD44 and its ligand, hyaluronan, contribute to late stages of cancer, including the invasive behavior and metastasis to bones, which is common among lung carcinomas (Hiraga et al. 2013). CD44 is abundantly expressed on NSCLC cells (Luo et al. 2014); this property could facilitate cancer cell invasion into hyaluronan-rich sites in bone marrow matrices. Thus, targeting the p38MAPK-hyaluronan axis could have important treatment benefits beyond targeting the initial steps of lung tumorigenesis.

\section{Materials and methods}

Mouse strains

To generate $\mathrm{p} 38^{\mathrm{Y} 182 \mathrm{~F}}$ and $\mathrm{p} 38^{\mathrm{T} 180 \mathrm{~A}}$ knock-in mice, the previously described targeting vector (Wong et al. 2009) was used that contained the equivalent of $4.5 \mathrm{~kb}$ of mouse DNA with an exon containing the phosphorylation sites of $\mathrm{p} 38 \mathrm{MAPK}$. The phosphorylation sites were mutated by site-directed mutagenesis. Targeted embryonic stem clones were generated, positive clones were screened and karyotyped, and one of the clones was used for blastocyst injection to generate mice in the $\mathrm{C} 57 \mathrm{Bl} / 6$ background. $\mathrm{P} 38^{\mathrm{Y} 182 \mathrm{~F} /+}$ mice were interbred to generate littermates with the following genotypes: $\mathrm{p} 38^{+/+}$(wild type) and $\mathrm{p} 38^{\mathrm{Y} 182 \mathrm{~F} / \mathrm{Y} 182 \mathrm{~F}}\left(\mathrm{p} 38^{\mathrm{ki} / \mathrm{ki}}\right)$. MEFs were purified from $12.5-\mathrm{d}$ embryos. P38 ${ }^{\mathrm{fl} / \mathrm{fl}}$ mice were 
obtained from RIKEN [C57BL/6-TgH(p38)/118] (Nishida et al. 2004), and hematopoietic-specific Cre-line Mxl-cre [C.Cg-Tg (Mx1-cre)1Cgn/J], S100A4-cre (FSP1-cre), and p53-deficient mice $\left(\mathrm{p} 53^{-/-}\right)$and mice with somatic activation of K-Ras ${ }^{\text {G12D }}$ were from the Jackson laboratory. To induce activation of $\mathrm{Mx} 1$ promoter, mice were injected at 4-5 wk of age with $600 \mu \mathrm{g}$ of p-I-C per mouse eight times, twice per week. For xenografts experiments, either nude mice or NSG mice were used. For the K-ras ${ }^{\mathrm{G} 12 \mathrm{D}}$-driven lung tumorigenesis, the number of lung lesions was assessed at 10 wk of age unless otherwise specified.

\section{Primary cell isolation and cell culture conditions}

For primary lung fibroblasts, lungs were perfused with PBS, cut into small pieces, and digested in $2 \mathrm{mg} / \mathrm{mL}$ collagenase IV, 1 $\mathrm{mg} / \mathrm{mL}$ dispase, and $0.1 \mathrm{mg} / \mathrm{mL}$ DNase I in DMEM/F12 medium. Before plating in DMEM/F12 medium supplemented with $15 \%$ FCS, cells were passed through a $100-\mu \mathrm{m}$ cell strainer and pretreated for $2 \mathrm{~min}$ with hypotonic red cell lysis buffer. The purity of primary lung fibroblasts was confirmed with no contamination by other cell types (Supplemental Fig. S3A). To establish a primary mouse lung cancer cell line, tumor lesions from $\mathrm{K}-\mathrm{ras}^{\mathrm{G} 12 \mathrm{D} /+} / \mathrm{p} 53^{-/-}$mice or $\mathrm{p} 38^{\mathrm{ki} / \mathrm{ki}} / \mathrm{p} 53^{-/-}$were excised, digested into single-cell suspension, and plated in $50 \%$ Matrigel (BD) supplemented with B27, $20 \mathrm{ng} / \mathrm{mL}$ EGF, and $20 \mathrm{ng} / \mathrm{mL}$ bFGF in DMEM/F12 medium. Once tumor cells formed visible spheroids, cells were resuspended and plated onto plastic for propagation.

For CAF induction, lung fibroblasts were serum-starved for $2 \mathrm{~d}$ and treated with $50 \mathrm{ng} / \mathrm{mL}$ recombinant TGF- $\beta 1$ (Dapcel, Inc.) for another $2 \mathrm{~d}$. Conditioned medium used for treatment was collected from lung cancer cells cultivated for $3 \mathrm{~d}$ in medium supplemented with $0.5 \%$ FCS. Recombinant Wnt3a and R-spondin were used at a concentration of $50 \mathrm{ng} / \mathrm{mL}(\mathrm{R} \& \mathrm{D})$, and TNFa was used at a concentration of $100 \mathrm{ng} / \mathrm{mL}$.

MEFs, LLC cells, and established mouse primary lung cancer cells were maintained in DMEM supplemented with 10\% FCS (Hyclone) and antibiotics. Primary human lung cancer cell lines T27 and T24 were cultivated in DMEM/F12 medium supplemented with $2 \%$ FCS, B27, and $20 \mathrm{ng} / \mathrm{mL}$ EGF. Next-generation sequencing (NGS)-based analysis of amplicons for the most common mutations of NSCLC was performed for primary human lung cancer cells used in studies (T27 and T24). T27 cells carry the NRAS mutation in codon R68T; common mutations were not identified in T24 cells.

\section{Sphere-forming assay}

Human or mouse lung cancer cells $\left(1 \times 10^{4}\right.$ cells per well for mouse K-ras/p53 $53^{-/-}$cells or $3 \times 10^{4}$ cells per well for human $\mathrm{T} 27$ and T24 cells) were plated in triplicate in ultralow attachment six-well plates (Costar) in $2 \mathrm{~mL}$ of sphere DMEM/F12 medium supplemented with $4 \%$ BSA, B27, $20 \mathrm{ng} / \mathrm{mL}$ EGF, and $20 \mathrm{ng} /$ $\mathrm{mL}$ bFGF. For coculture experiments, tumor cells were mixed with three times excess of primary lung fibroblasts in triplicate. After 6-8 d, images of formed spheres were taken, the number of spheroids was counted, all spheroids were resuspended in trypsin, and the number of cells was counted manually using a hematology cell counter.

\section{Tumor cell xenografts}

P38 ${ }^{+/+}$wild-type MEFs or $\mathrm{p} 38^{\mathrm{ki} / \mathrm{ki}}$ MEFs were transformed with $\mathrm{E} 1 \mathrm{~A}$ and Rav ${ }^{\mathrm{V} 12}$ oncogenes, and established stable cell lines were xenografted into nude mice subcutaneously as $1 \times 10^{5}$ cells per flank with at least three mice per group. The same cell num- ber was used for xenografting of primary mouse lung cancer cells established from $\mathrm{p} 38^{++}$and $\mathrm{p} 38^{-/-}$mice in the Kras/p53 $53^{-/-}$background. Mice were sacrificed once tumor size reached $1.5-2 \mathrm{~cm}$ in diameter. Solid tumors were excised, weighed, and imaged. For coinjection of K-ras/p53 ${ }^{-/-}$mouse lung cancer cells with mouse fibroblasts, $1 \times 10^{5}$ cancer cells were mixed in Heanks solution with $3 \times 10^{5}$ mouse lung fibroblasts and injected subcutaneously into nude mice. For the orthotopic model, $1 \times 10^{6}$ human T27 lung cancer cells were intravenously injected into NSG mice, and tumor progression was monitored weekly by luciferase readings. Five microliters of tail vein blood was diluted in $100 \mu \mathrm{L}$ of luciferase assay reagent supplemented with the substrate (Promega) followed by reading using a TECAN plate reader. Mice were sacrificed 6 wk after injection.

\section{Statistical analysis}

Values are means \pm SD. Comparison of mean values between groups was evaluated by two-tailed Student's $t$-test using GraphPad Prizm. $P$-values $<0.05$ were considered significant. The experiments with three biological replicates were always done in triplicate. Any $P$-value $<0.05$ is designated with one asterisk, $P$ value $<0.01$ is designated with two asterisks, and $P$-value $<0.001$ is designated with three asterisks. "NS" indicates nonsignificant.

\section{Acknowledgments}

We are grateful to Heike Wollmann and Jingxian Zhang (Institute of Molecular and Cell Biology [IMCB]) for NGS service, and the Advanced Molecular Pathology Laboratory of the Institute of Molecular and Cell Biology for histology. The research of the Bulavin Dmitry laboratory is supported by a Foundation ARC grant (France); A.B. and H.M.L. were supported by the Agency for Science Technology and Research's (A*STAR) Joint Council Office project grant 14302FG090 (Singapore).

\section{References}

Adams RH, Porras A, Alonso G, Jones M, Vintersten K, Panelli S, Valladares A, Perez L, Klein R, Nebreda AR. 2000. Essential role of p38a MAP kinase in placental but not embryonic cardiovascular development. Mol Cell 6: 109-116.

Alspach E, Flanagan KC, Luo X, Ruhland MK, Huang H, Pazolli E, Donlin MJ, Marsh T, Piwnica-Worms D, Monahan J, et al. 2014. p38MAPK plays a crucial role in stromal-mediated tumorigenesis. Cancer Discov 4: 716-729.

Brancho D, Tanaka N, Jaeschke A, Ventura JJ, Kelkar N, Tanaka Y, Kyuuma M, Takeshita T, Flavell RA, Davis RJ. 2003. Mechanism of p38 MAP kinase activation in vivo. Genes Dev 17: 1969-1978.

Bremnes RM, Donnem T, Al-Saad S, Al-Shibli K, Andersen S, Sirera R, Camps C, Marinez I, Busund LT. 2011. The role of tumor stroma in cancer progression and prognosis: emphasis on carcinoma-associated fibroblasts and non-small cell lung cancer. J Thorac Oncol 6: 209-217.

Bulavin DV, Fornace AJ Jr. 2004. p38 MAP kinase's emerging role as a tumor suppressor. Adv Cancer Res 92: 95-118.

Camenisch TD, Spicer AP, Brehm-Gibson T, Biesterfeldt J, Augustine ML, Calabro A Jr, Kubalak S, Klewer SE, McDonald JA. 2000. Disruption of hyaluronan synthase-2 abrogates normal cardiac morphogenesis and hyaluronan-mediated transformation of epithelium to mesenchyme. J Clin Invest 106: 349-360. 
Chen Z, Fillmore CM, Hammerman PS, Kim CF, Wong KK. 2014. Non-small-cell lung cancers: a heterogeneous set of diseases. Nat Rev Cancer 14: 535-546.

Dotto GP, Weinberg RA, Ariza A. 1988. Malignant transformation of mouse primary keratinocytes by Harvey sarcoma virus and its modulation by surrounding normal cells. Proc Nat1 Acad Sci 85: 6389-6393.

Elenitoba-Johnson KS, Jenson SD, Abbott RT, Palais RA, Bohling SD, Lin Z, Tripp S, Shami PJ, Wang LY, Coupland RW, et al. 2003. Involvement of multiple signaling pathways in follicular lymphoma transformation: p38-mitogen-activated protein kinase as a target for therapy. Proc Natl Acad Sci 100: 7259-7264.

El-Nikhely N, Larzabal L, Seeger W, Calvo A, Savai R. 2012. Tumor-stromal interactions in lung cancer: novel candidate targets for therapeutic intervention. Expert Opin Investig Drugs 21: 1107-1122.

Gascard P, Tlsty TD. 2016. Carcinoma-associated fibroblasts: orchestrating the composition of malignancy. Genes Dev 30: 1002-1019.

Greenberg AK, Basu S, Hu J, Yie TA, Tchou-Wong KM, Rom WN, Lee TC. 2002. Selective p38 activation in human non-small cell lung cancer. Am J Respir Cell Mol Biol 26: 558-564.

Hiraga T, Ito S, Nakamura H. 2013. Cancer stem-like cell marker CD44 promotes bone metastases by enhancing tumorigenicity, cell motility, and hyaluronan production. Cancer Res 73: 4112-4122.

Hui L, Bakiri L, Mairhorfer A, Schweifer N, Haslinger C, Kenner L, Komnenovic V, Scheuch H, Beug H, Wagner EF. 2007. p38a suppresses normal and cancer cell proliferation by antagonizing the JNK-c-Jun pathway. Nat Genet 39: 741-749.

Igea A, Nebreda AR. 2015. The stress kinase p38a as a target for cancer therapy. Cancer Res 75: 3997-4002.

Johnson L, Mercer K, Greenbaum D, Bronson RT, Crowley D, Tuveson DA, Jacks T. 2001. Somatic activation of the K-ras oncogene causes early onset lung cancer in mice. Nature 410: $1111-1116$.

Joyce JA, Pollard JW. 2009. Microenvironmental regulation of metastasis. Nat Rev Cancer 9: 239-252.

Junttila MR, de Sauvage FJ. 2013. Influence of tumour micro-environment heterogeneity on therapeutic response. Nature 501: 346-354.

Kakizaki I, Kojima K, Takagaki K, Endo M, Kannagi R, Ito M, Maruo Y, Sato H, Yasuda T, Mita S, et al. 2004. A novel mechanism for the inhibition of hyaluronan biosynthesis by 4methylumbelliferone. J Biol Chem 279: 33281-33289.

Koyama H, Hibi T, Isogai Z, Yoneda M, Fujimori M, Amano J, Kawakubo M, Kannagi R, Kimata K, Taniguchi S, et al. 2007. Hyperproduction of hyaluronan in neu-induced mammary tumor accelerates angiogenesis through stromal cell recruitment: possible involvement of versican/PG-M. Am J Pathol 170: 1086-1099.

Koyama H, Kobayashi N, Harada M, Takeoka M, Kawai Y, Sano K, Fujimori M, Amano J, Ohhashi T, Kannagi R, et al. 2008. Significance of tumor-associated stroma in promotion of intratumoral lymphangiogenesis: pivotal role of a hyaluronan-rich tumor microenvironment. Am J Pathol 172: 179-193.

Kultti A, Pasonen-Seppanen S, Jauhiainen M, Rilla KJ, Karna R, Pyoria E, Tammi RH, Tammi MI. 2009. 4-methylumbelliferone inhibits hyaluronan synthesis by depletion of cellular UDP-glucuronic acid and downregulation of hyaluronan synthase 2 and 3. Exp Cell Res 315: 1914-1923.
Li Y, Heldin P. 2001. Hyaluronan production increases the malignant properties of mesothelioma cells. Br J Cancer 85: 600-607.

Luo Z, Wu RR, Lv L, Li P, Zhang LY, Hao QL, Li W. 2014. Prognostic value of CD44 expression in non-small cell lung cancer: a systematic review. Int I Clin Exp Pathol 7: 3632-3646.

Meran S, Luo DD, Simpson R, Martin J, Wells A, Steadman R, Phillips AO. 2011. Hyaluronan facilitates transforming growth factor- $\beta 1$-dependent proliferation via CD44 and epidermal growth factor receptor interaction. J Biol Chem 286: 17618-17630.

Nishida K, Yamaguchi O, Hirotani S, Hikoso S, Higuchi Y, Watanabe T, Takeda T, Osuka S, Morita T, Kondoh G, et al. 2004. p38a mitogen-activated protein kinase plays a critical role in cardiomyocyte survival but not in cardiac hypertrophic growth in response to pressure overload. Mol Cell Biol 24: 10611-10620.

Okuda H, Kobayashi A, Xia B, Watabe M, Pai SK, Hirota S, Xing F, Liu W, Pandey PR, Fukuda K, et al. 2012. Hyaluronan synthase HAS2 promotes tumor progression in bone by stimulating the interaction of breast cancer stem-like cells with macrophages and stromal cells. Cancer Res 72: 537-547.

Orimo A, Gupta PB, Sgroi DC, Arenzana-Seisdedos F, Delaunay T, Naeem R, Carey VJ, Richardson AL, Weinberg RA. 2005. Stromal fibroblasts present in invasive human breast carcinomas promote tumor growth and angiogenesis through elevated SDF-1/CXCL12 secretion. Cell 121: 335-348.

Pomerance M, Quillard J, Chantoux F, Young J, Blondeau JP. 2006. High-level expression, activation, and subcellular localization of p38-MAP kinase in thyroid neoplasms. J Pathol 209: 298-306.

Shiga K, Hara M, Nagasaki T, Sato T, Takahashi H, Takeyama H. 2015. Cancer-associated fibroblasts: their characteristics and their roles in tumor growth. Cancers (Basel) 7: 2443-2458.

Tamura K, Sudo T, Senftleben U, Dadak AM, Johnson R, Karin M. 2000. Requirement for $\mathrm{p} 38 \mathrm{a}$ in erythropoietin expression: a role for stress kinases in erythropoiesis. Cell 102: 221-231.

Toole BP. 2001. Hyaluronan in morphogenesis. Semin Cell Dev Biol 12: 79-87.

Toole BP. 2004. Hyaluronan: from extracellular glue to pericellular cue. Nat Rev Cancer 4: 528-539.

Ventura JJ, Tenbaum S, Perdiguero E, Huth M, Guerra C, Barbacid M, Pasparakis M, Nebreda AR. 2007. p38a MAP kinase is essential in lung stem and progenitor cell proliferation and differentiation. Nat Genet 39: 750-758.

Wong ES, Le Guezennec X, Demidov ON, Marshall NT, Wang ST, Krishnamurthy J, Sharpless NE, Dunn NR, Bulavin DV. 2009. p38MAPK controls expression of multiple cell cycle inhibitors and islet proliferation with advancing age. Dev Cell 17: 142-149.

Yan Y, Zuo X, Wei D. 2015. Concise review: emerging role of CD44 in cancer stem cells: a promising biomarker and therapeutic target. Stem Cells Transl Med 4: 1033-1043.

Zhang Y, Hu H, Wang R, Ye T, Pan Y, Wang L, Li H, Li Y, Shen L, Yu Y, et al. 2014. Synchronous non-small cell lung cancers: diagnostic yield can be improved by histologic and genetic methods. Ann Surg Oncol 21: 4369-4374.

Zoltan-Jones A, Huang L, Ghatak S, Toole BP. 2003. Elevated hyaluronan production induces mesenchymal and transformed properties in epithelial cells. J Biol Chem 278: 45801-45810. 


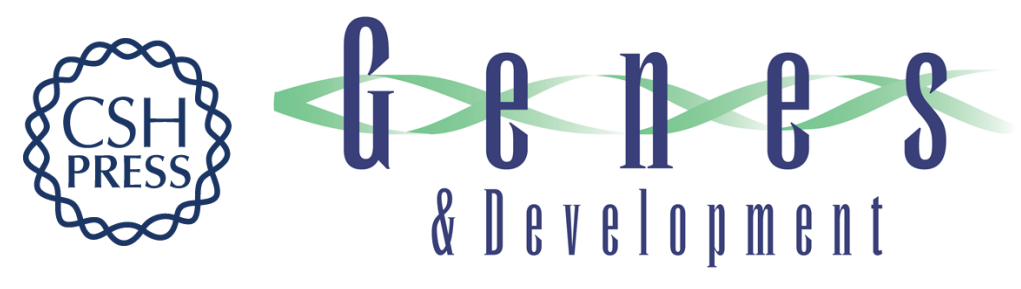

\section{p38MAPK builds a hyaluronan cancer niche to drive lung tumorigenesis}

Anna Brichkina, Thomas Bertero, Hui Mun Loh, et al.

Genes Dev. 2016, 30:

Access the most recent version at doi:10.1101/gad.290346.116

\section{Supplemental http://genesdev.cshlp.org/content/suppl/2016/12/22/30.23.2623.DC1 Material}

References This article cites 38 articles, 12 of which can be accessed free at: http://genesdev.cshlp.org/content/30/23/2623.full.html\#ref-list-1

Creative This article is distributed exclusively by Cold Spring Harbor Laboratory Press for the first Commons six months after the full-issue publication date (see

License http://genesdev.cshlp.org/site/misc/terms.xhtml). After six months, it is available under a Creative Commons License (Attribution-NonCommercial 4.0 International), as described at http://creativecommons.org/licenses/by-nc/4.0/.

Email Alerting Receive free email alerts when new articles cite this article - sign up in the box at the top Service right corner of the article or click here.

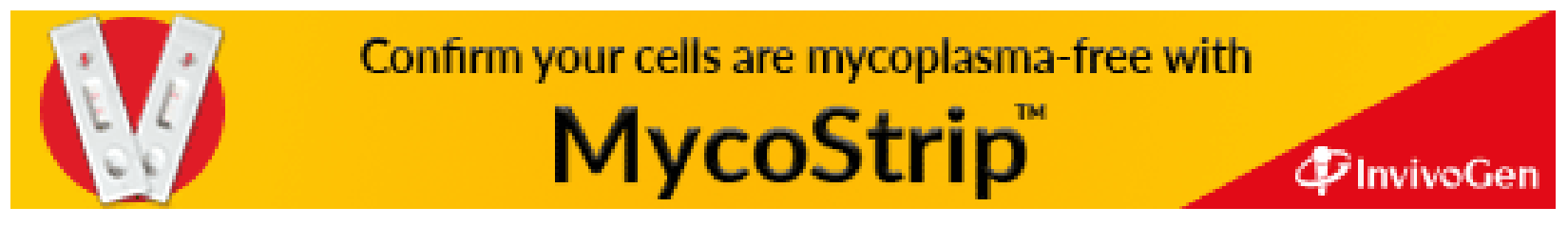

